\title{
Conductive and photoactive nature of conjugated polymer based on thiophene functionalized thiazole or benzothiadiazole
}

\author{
K. Mahesh ${ }^{1}$, S. Karpagam ${ }^{1 *}$, F. Goubard ${ }^{2}$ \\ ${ }^{1}$ Department of Chemistry, School of Advanced Sciences, VIT University, Vellore-14, Tamil Nadu, India \\ ${ }^{2}$ LPPI, Université de Cergy-Pontoise, 5 mail Gay Lussac, Neuville Sur Oise, 95031 Cergy-Pontoise Cedex, France
}

Received 24 August 2017; accepted in revised form 30 October 2017

\begin{abstract}
New poly (thiophene vinyl thiazole) (PTVT) and poly (thiophene vinyl benzothiadiazole) (PTVBT) was synthesized by Wittig condensation route. The absorption maximum of PTVT and PTVBT appeared at 376 and $410 \mathrm{~nm}$ in a solution state, and it was red-shifted to 417 and $510 \mathrm{~nm}$ in a thin film state. The optical band gaps were 1.7 and $1.5 \mathrm{eV}$ calculated from thin film absorption edges of the polymer. The photoluminescence spectra of PTVT and PTVBT have an emission peak at $457 \mathrm{~nm}$ with bluish green and $487 \mathrm{~nm}$ with greenish-yellow fluorescence in THF solution. Both polymers showed a short fluorescence decay time $\left(\tau_{1}\right)$ of 2.31 and 0.73 ns respectively. Furthermore, the aggregation-caused quenching (ACQ) phenomenon observed in both polymers in decreased fluorescence intensity with different water fractions. The lower electrochemical band gaps were achieved for both polymers $(1.4$, and $1.3 \mathrm{eV})$ from cyclic voltammetry. Both polymers have a granular shaped morphology with good surface roughness was observed using AFM. High thermal stability was observed with $8 \%$ weight loss at $400^{\circ} \mathrm{C}$ for PTVT and $6 \%$ weight loss at $460^{\circ} \mathrm{C}$ for PTVBT. The highest electrical conductivity was observed from electrochemical impedance measurement which was $7.68 \cdot 10^{-6} \Omega^{-1} \cdot \mathrm{cm}^{-1}$ for PTVBT.
\end{abstract}

Keywords: thermal properties, poly(p-phenylenevinylene), photoluminescence, band gap, impedance

\section{Introduction}

Growth of conjugated organic polymer materials was saturated in the last 10 years, but still more attention is paid to them because of having potential application in optoelectronics such as organic photovoltaic devices (PSCs) [1], organic light emitting diodes (OLEDs) [2], organic thin film transistors [3], solid state lasers and chemical sensors [4] etc. The large variety of applications of conjugated polymers is due both to the great diversity of search of photophysical properties and to the multiplicity of achievable design as molecular structure. Conjugated polymers are having many merits, such as mechanical flexibility, low cost, facility of forming large areas, efficient and easy of processability compared with inorganic materials.
Among the various kinds of conjugated polymers, poly( $p$-phenylene vinylene)s (PPVs) and its derivatives are widely investigated, because of their processability, stability and optical and electrical characteristics. By attentively selecting the conjugated polymer backbone and side chains, we can alter a variety of photoluminescence and electroluminescence colors. Till now PPV has been reported with a variety of substituents such as alkoxy [5], fluorenyl [6], phenyl [7], alkyl [8], cyano group [9] or halides [10]. Among these PPV conjugated polymers, alkoxy PPV conjugated polymers with poor solubility are detrimental for device elaboration. Many conjugated polymers are having poor solubility while performing device fabrications. Through the incorporation of flexible

${ }^{*}$ Corresponding author, e-mail: skarpagam80@yahoo.com (C) BME-PT 
and long side chains on the conjugated polymer backbone, we could achieve solubility, thermal stability and good film-forming property of aromatic conjugated polymers $[11,12]$. These flexible and bulkier side chains create steric hindrance among the conjugated polymer backbones. This steric effect can be controlled by the conjugation length of the polymer results in the change of the fluorescence colour [13]. Our main objective is to obtain low band gap conjugated polymer with thiophene (as donor) and thiazole (as acceptor) moieties. We proposed to combine these compounds with alkoxy phenylene vinylenes in order to both increase photoluminescence and lower the electrochemical band gap. The assertive approach is incorporating thiophene with thiazole to create the donor-acceptor system to lower the band gap and stimulate the intrachain charge transfer of the polymer [14]. Thiophene is having an excellent hole transporting ability, good light-harvesting properties and great thermal and environmental stability $[15,16]$. Thiazole and 2,1,3-benzothiadiazole are good fluorescent chromophores and strong electron withdrawing units due to the imine group $(-\mathrm{C}=\mathrm{N}-)$ and are used to lower the bandgap $[17,18]$.

However, numerous organic polymers in dilute solution display different photophysical properties compared with the concentrated solution. For instance, it is a general phenomenon that luminescence is usually weakened or quenched at elevated concentrations. This concentration quenching is mostly originated from the formation of aggregates, which has commonly alluded as 'ACQ' [19]. It has been perceived that most of the aromatic luminophores have experienced the ACQ effect, which has been indicated in the outline of Photophysics of aromatic molecules in 1970 [19]. Furthermore, the ACQ effect might be more demand in the field of OLEDs [20].

The present article deals with the synthesis, characterization and luminescence properties of new low band gap bluish green and greenish yellow emitting conjugated polymers (PTVT and PTVBT). Both polymers exhibited ACQ effect at higher concentrated water fraction solutions $\left(f_{\mathrm{w}}\right)$. PTVT consisted of repeating units of thiophene bonded hexyloxy phenylene vinylene and thiazole and PTVBT consisted of repeating units of thiophene bonded dodecyloxy phenylene vinylene and benzothiadiazole. In the reported polymers, monomers are connected with ethylene linkages. The linkages have given the planarity, flexibility and eliminated the torsional strain between donor and acceptor on the entire conjugated system [21]. Furthermore, we examined the optical, electrochemical, surface morphology, conductivity and thermal properties of the synthesized polymer.

\section{Materials and methods}

\subsection{Reagents and solvents}

Hydroquinone, bromine, 1-bromo hexane, 1-bromododecane, tri-butylvinyltin, $\mathrm{Pd}\left(\mathrm{PPh}_{3}\right)_{4}$, 5-bromo2-thiophene carboxaldehyde, $\mathrm{Pd}(\mathrm{OAc})_{2}$, 4,5-dimethylthiazole, 4,5-dimethyl-1,2-phenylenediamine, thionyl chloride, triethylamine, $\mathrm{N}$-bromosuccinimide, benzoyl peroxide, triphenylphosphine, sodium hydride were purchased from Sigma-Aldrich, Bangalore, India. Solvents such as tetrahydrofuran, hexane, ethyl acetate, carbon tetrachloride, acetonitrile, dichloromethane, and $N, N$-dimethyl formamide were purchased from Sd-fine chemicals, India. All solvents were purified by distillation before the synthesis as per standard procedures.

\subsection{Characterization methods}

FT-IR analysis was studied through Thermo Nicolet 330 FT-IR spectrometer, Madison, WI USA. The ${ }^{1} \mathrm{H}$ NMR and ${ }^{13} \mathrm{C}$ NMR spectra were recorded on Bruker Advance III $400 \mathrm{MHz}$ spectrometer using tetramethylsilane as an internal standard. The UV-visible absorption spectra were characterized on JASCOV-670 FT-IR spectrometer, Japan. The fluorescence emission of the polymers was performed on Perkin Elmer LS45 fluorescence spectrometer, Singapore. The lifetime measurements were carried out with Jobin Yvon FLUOROLOG-FL3-111 spectrofluorometer. The aggregation changes were observed in ZEISS (EVO18) scanning electron microscope, USA. Polymer thin films are spin-coated on a silica glass substrate by using apex spin NXG-P1 instrument, Kolkata, India. The surface morphological images were taken using on Nanosurf Easyscan 2 AFM instrument, Switzerland. Cyclic voltammogram peaks were recorded on CH-I 660C instrument, Austin, USA. These electrochemical studies carried out using anhydrous acetonitrile solvent with the three-electrode system. $\mathrm{Ag} / \mathrm{AgCl}$ as a reference electrode, platinum wire as a counter electrode, polymer coated ITO glass as a working electrode and tetrabutylammonium hexafluorophosphate $\left(\mathrm{Bu}_{4} \mathrm{NPF}_{6}\right)(0.1 \mathrm{M})$ as the electrolyte. TGA analysis carried out using SDT Q600 V20.9 build 20 instrument under nitrogen flow rate $100 \mathrm{~mL} / \mathrm{min}$, USA. The electrochemical impedance 
conductivity was carried out using CH-I 760C instrument with a conventional three-electrode system using $\mathrm{Ag} / \mathrm{AgCl}$ as a reference electrode, platinum wire as a counter electrode, polymer coated glassy carbon electrode (GCE, area $0.0707 \mathrm{~cm}^{2}$ ) as a working electrode. The molecular weights of the intermediates were obtained from Perkin Elmer Clarus 680GC-MS spectrometer, Singapore. The polymer molecular weights were observed by gel permeation chromatography using a Waters-RID 2414 instrument.

\subsection{Synthetic procedure}

\subsubsection{Synthesis of 2,5-dibromo hydroquinone (2)}

To a stirred solution of hydroquinone ( $5 \mathrm{~g}, 45.4 \mathrm{mmol})$ in acetic acid $(50 \mathrm{~mL})$ were added to a mixture of bromine $(5.8 \mathrm{~mL}, 113.52 \mathrm{mmol})$ in acetic acid $(6 \mathrm{~mL})$ under cold condition via syringe. After completion of addition, the reaction mixture was stirred at room temperature for $20 \mathrm{~h}$. After the reaction mixture was diluted with water, resulting precipitation was filtered and washed with cold water for the removal of acetic acid traces. Then the resulting precipitate was dried and kept under vacuum oven to get a brown color solid. Yield: $72 \%$, m.p: $182-185^{\circ} \mathrm{C} .{ }^{1} \mathrm{H}$ NMR $(400 \mathrm{MHz}$, $\left.\mathrm{CDCl}_{3}, \delta \mathrm{ppm}\right): 7.0\left(\mathrm{~s}, 2 \mathrm{H}\right.$, aromatic $\left.{ }^{1} \mathrm{H}\right), 3.4(\mathrm{~s}, 2 \mathrm{H}$, -OH). $\left.{ }^{13} \mathrm{C} \mathrm{NMR} \mathrm{(100} \mathrm{MHz,} \mathrm{CDCl}_{3}, \delta \mathrm{ppm}\right): 147.2$, 119.4, 108.2 (aromatic C). Molecular weight calculated for $\mathrm{C}_{6} \mathrm{H}_{4} \mathrm{Br}_{2} \mathrm{O}_{2}(\mathrm{~m} / z)=267.90$, found, 267.98 .

\subsubsection{Synthesis of 1,4 -dibromo-2,5-bis- hexyloxybenzene (3a)}

A flask was charged with a mixture of 2,5-dibromo hydroquinone (2) $(0.5 \mathrm{~g}, 1.86 \mathrm{mmol})$ and $25 \mathrm{~mL}$ of DMF. To this stirred solution $\mathrm{K}_{2} \mathrm{CO}_{3}(0.9 \mathrm{~g}$, $6.53 \mathrm{mmol}$ ) was added pinch wise. Then, 1-bromohexane $(0.67 \mathrm{~mL}, 4.85 \mathrm{mmol})$ was slowly added to the reaction mixture. The resulting mixture was stirred at $90^{\circ} \mathrm{C}$ under nitrogen condition for $12 \mathrm{~h}$. The dark brown color solution was diluted with ice cold water and extracted with ethyl acetate and dried over $\mathrm{Na}_{2} \mathrm{SO}_{4}$. After evaporation of ethyl acetate, the crude product was purified by column chromatography using hexane as eluent to get a white color solid. Yield: $61 \%$, m.p: $50-53{ }^{\circ} \mathrm{C} .{ }^{1} \mathrm{H}$ NMR $(400 \mathrm{MHz}$, $\left.\mathrm{CDCl}_{3}, \delta \mathrm{ppm}\right): 7.0\left(\mathrm{~s}, 2 \mathrm{H}\right.$, aromatic $\left.{ }^{1} \mathrm{H}\right), 3.8(\mathrm{t}, 4 \mathrm{H}$, $\left.-\mathrm{OCH}_{2}-\right), 1.7-0.8\left(\mathrm{~m}, 22 \mathrm{H},-\mathrm{CH}_{2}\right.$ and $\left.-\mathrm{CH}_{3}\right)$. ${ }^{13} \mathrm{C}$ NMR (100 MHz, $\left.\mathrm{CDCl}_{3}, \delta \mathrm{ppm}\right): 150.1,118.5$, 111.1 (aromatic C), 70.3, 30.9, 29.0, 25.6, 22.5, 14.0 (hexyl chain $\mathrm{C}$ ). Molecular weight calculated for $\mathrm{C}_{18} \mathrm{H}_{28} \mathrm{Br}_{2} \mathrm{O}_{2}(\mathrm{~m} / \mathrm{z})=436.22$, found, 436.3.

\subsubsection{Synthesis of 1,4-bis-hexyloxy-2,5- divinylbenzene (4a)}

Compound (3a) (1.2 g, $2.75 \mathrm{mmol}$ ) was dissolved in $150 \mathrm{~mL}$ of toluene. To this stirred solution tri-butyl vinyl tin $(1.85 \mathrm{~mL}, 6.32 \mathrm{mmol}), \mathrm{Pd}\left(\mathrm{PPh}_{3}\right)_{4}(0.15 \mathrm{~g}$, $0.137 \mathrm{mmol})$ were added under $\mathrm{N}_{2}$ condition. The resulting mixture was stirred at $120^{\circ} \mathrm{C}$ under the $\mathrm{N}_{2}$ condition for $40 \mathrm{~h}$. After the reaction mixture was cooled to room temperature, the crude product was diluted with water and extracted with diethyl ether. The organic phase was washed twice with brine solution and dried over $\mathrm{Na}_{2} \mathrm{SO}_{4}$. After evaporation of organic layer, the crude product was purified by column chromatography by using of hexane as eluent. Yield: $40 \%$, m.p: $45^{\circ} \mathrm{C} .{ }^{1} \mathrm{H}$ NMR $\left(400 \mathrm{MHz}, \mathrm{CDCl}_{3}\right.$, $\delta \mathrm{ppm}): 7.0(\mathrm{dd}, 2 \mathrm{H}$, germinal vinyl-H), $6.91(\mathrm{~s}, 2 \mathrm{H}$, $\mathrm{Ar}-\mathrm{H}), 5.67(\mathrm{~d}, 2 \mathrm{H}$, cis-vinyl-H), $5.18(\mathrm{~d}, 2 \mathrm{H}$, transvinyl $\mathrm{H}), 3.95\left(\mathrm{t}, 4 \mathrm{H},-\mathrm{OCH}_{2}-\right), 1.7-0.8(\mathrm{~m}, 22 \mathrm{H}$, $-\mathrm{CH}_{2}-$ and $\left.-\mathrm{CH}_{3}\right) .{ }^{13} \mathrm{C} \mathrm{NMR}\left(100 \mathrm{MHz}, \mathrm{CDCl}_{3}\right.$, $\delta$ ppm): 150.6, 131.5, 127.2 (aromatic C), 114.0, 110.6 (vinyl C), 69.37, 31.61, 29.7, 25.8, 22.6, 14.04 (hexyl chain C). Molecular weight calculated for $\mathrm{C}_{22} \mathrm{H}_{34} \mathrm{O}_{2}(\mathrm{~m} / \mathrm{z})=330.50$, found, 330.57 .

\subsubsection{Synthesis of monomer $1\left(M_{1}\right)$}

A flask was charged with mixture of compound (4a) (1 g, $1.99 \mathrm{mmol})$, 5-bromo-2-thiophene carboxaldehyde $(0.76 \mathrm{~g}, 3.98 \mathrm{mmol}), \mathrm{Pd}(\mathrm{OAc})_{2}(0.009 \mathrm{~g}$, $0.039 \mathrm{mmol})$, triphenyl phosphine $(0.2 \mathrm{~g}, 0.79 \mathrm{mmol})$ and $\mathrm{K}_{2} \mathrm{CO}_{3}(0.55 \mathrm{~g}, 3.98 \mathrm{mmol})$ in DMF. After the flask was degassed and purged with nitrogen for $15 \mathrm{~min}$. The reaction mixture was heated at $140^{\circ} \mathrm{C}$ for $40 \mathrm{~h}$. Then it was cooled and diluted with water, and then extracted with ethyl acetate. After evaporation of ethyl acetate, the crude product was purified by column chromatography by using of 1:9 ratio of ethyl acetate: hexane as eluent to get a yellow color solid. Yield: $72 \%$. m.p: $40{ }^{\circ} \mathrm{C} .{ }^{1} \mathrm{H}$ NMR $(400 \mathrm{MHz}$, $\mathrm{CDCl}_{3}, \delta \mathrm{ppm}$ ): 9.79 (s, 2H, $\left.-\mathrm{CHO}\right), 7.60(\mathrm{~d}, 2 \mathrm{H}$, Thiophene H), 7.29 (d, 2H, thiophene H), 7.18 (d, $2 \mathrm{H}$, olefinic $\mathrm{H}), 7.00$ (d, 2H, olefinic $\mathrm{H}), 6.97$ (s, 2H, phenylene $\mathrm{H}), 3.90\left(\mathrm{~m}, 4 \mathrm{H},-\mathrm{OCH}_{2}-\right), 1.70-0.8(\mathrm{~m}$, $22 \mathrm{H},-\mathrm{CH}_{2}$ and $\left.-\mathrm{CH}_{3}\right) .{ }^{13} \mathrm{C} \mathrm{NMR}\left(100 \mathrm{MHz}, \mathrm{CDCl}_{3}\right.$, ppm): 182.5 (-CHO), 147.2, 141.7, 137.3, 136.0, 128.3 127.1, 126.1, 124.2 (aromatic C), 31.5, 29.7, 29.5, 29.3, 22.7, 14.1 (hexyl C). Compounds 3b, 4b and monomer-2 $\left(\mathrm{M}_{2}\right)$ were synthesized by using preparation methods of $3 \mathrm{a}, 4 \mathrm{a}$ and $\mathrm{M}_{1}$. The hexyloxy chain was replaced with the dodecyloxy chain in $\mathrm{M}_{2}$. 


\subsubsection{Preparation of}

4,5-(triphenylphosphoniummethyl)thiazole dibromide (Monomer $3\left(\mathbf{M}_{3}\right)$ )

Monomer-3 $\left(\mathrm{M}_{3}\right)$ was synthesized according to our previous literature [27]. FTIR $\left(\mathrm{v} / \mathrm{cm}^{-1}\right): 3020.4$ (aromatic $\mathrm{C}-\mathrm{H}$ stretch), $1736.8(\mathrm{C}=\mathrm{C}$ bending), 1586 $(-\mathrm{C}=\mathrm{N}-$ stretch), 1432 (aromatic $\mathrm{C}-\mathrm{C}$ stretch), 745.4 (C-P), 685.2 (C-Br), 550.5 (P-Br). ${ }^{1} \mathrm{H}$ NMR (400 MHz, DMSO- $d_{6}, \delta$ ppm): 8.95 (s, $1 \mathrm{H}$, thiazole H), 7.96-7.66 (m, 30H, Phenyl H), 5.43 (s, 2H, $\left.-\mathrm{CH}_{2}-\right), 5.42\left(\mathrm{~s}, 2 \mathrm{H},-\mathrm{CH}_{2}-\right) .{ }^{13} \mathrm{C}$ NMR $(100 \mathrm{MHz}$, $\left.\mathrm{CDCl}_{3}, \delta \mathrm{ppm}\right): 154.21,154.17,153.90,153.81$, $135.41,135.39,133.92,133.82,130.32,130.20$, $117.63,116.78,116.54,116.44$ (phenyl-C), 21.07, $14.17\left(-\mathrm{CH}_{2}-\right)$.

\subsubsection{Preparation of 5,6-dimethyl-[2,1,3] benzothiadiazole (8)}

Compound $7(5 \mathrm{~g}, 36.71 \mathrm{mmol})$ and triethylamine (18.57 g, 183.55) were dissolved in DCM $(150 \mathrm{~mL})$ and cooled to $0^{\circ} \mathrm{C}$. Thionyl chloride $(8.73 \mathrm{~g}$, $73.42 \mathrm{mmol}$ ) was slowly dropped to the stirred solution. After that reaction mixture was refluxed for $6 \mathrm{~h}$, the reaction mixture was diluted with $300 \mathrm{~mL}$ of water and the dichloromethane phase was separated, washed with brine solution, and dried over anhydrous $\mathrm{Na}_{2} \mathrm{SO}_{4}$. The crude product was purified by using column chromatography on silica gel (1:9 ethyl acetate/hexane) to give compound 8 as colorless solid. Yield: $4 \mathrm{~g}, 70 \%$. mp: $72{ }^{\circ} \mathrm{C} .{ }^{1} \mathrm{H} \mathrm{NMR}$ (400 MHz, $\left.\mathrm{CDCl}_{3}, \delta \mathrm{ppm}\right): 7.71\left(\mathrm{~s}, 2 \mathrm{H}, \mathrm{Ar} \mathrm{H}^{1}\right)$, $2.42\left(\mathrm{~s}, 6 \mathrm{H},-\mathrm{CH}_{3}-\right) .{ }^{13} \mathrm{C} \mathrm{NMR}\left(100 \mathrm{MHz}, \mathrm{CDCl}_{3}\right.$, $\delta \mathrm{ppm}$ ): 154.27, 140.53, 119.77 (Ar C), 20.79 $\left(-\mathrm{CH}_{3}-\right)$.

\subsubsection{Preparation of 5,6-bis(bromomethyl) $[2,1,3]$ benzothiadiazole (9)}

Compound 8 (4 g, $24.35 \mathrm{mmol}$ ), $N$-bromosuccinimide (NBS) (8.66 g, $48.71 \mathrm{mmol}$ ), and benzoyl peroxide $(0.23 \mathrm{~g}, 0.97 \mathrm{mmol})$ were dissolved in $\mathrm{CCl}_{4}$ $(100 \mathrm{~mL})$ was refluxed for $6 \mathrm{~h}$. After the reaction mixture was cooled and succinimide salt was removed by filtration, and the filtrate was evaporated to give the compound 9 as the brown color solid. Yield: $6.5 \mathrm{~g}, 83 \%$. mp: $80{ }^{\circ} \mathrm{C} .{ }^{1} \mathrm{H}$ NMR $(400 \mathrm{MHz}$, $\left.\mathrm{CDCl}_{3}, \delta \mathrm{ppm}\right): 8.06$ (s, 2H, Ar H$\left.{ }^{1}\right), 4.84(\mathrm{~s}, 4 \mathrm{H}$, $\left.-\mathrm{CH}_{2}-\right) .{ }^{13} \mathrm{C} \mathrm{NMR}\left(400 \mathrm{MHz}, \mathrm{CDCl}_{3}, \delta \mathrm{ppm}\right)$ : $154.52,138.24,123.55$ ( $\mathrm{Ar} \mathrm{C}), 30.08\left(-\mathrm{CH}_{2}-\right)$.

\subsubsection{Preparation of 5,6-bis(triphenylphospho- niummethyl) $[2,1,3]$ benzothiadiazole dibromide (Monomer-4 $\left(\mathbf{M}_{\mathbf{4}}\right)$ )}

Compound 9 ( $2 \mathrm{~g}, 6.25 \mathrm{mmol})$, and triphenylphosphine ( $3.44 \mathrm{~g}, 13.13 \mathrm{mmol}$ ) were dissolved in $\mathrm{CH}_{3} \mathrm{CN}$ $(100 \mathrm{~mL})$ and $\mathrm{CH}_{2} \mathrm{Cl}_{2}(10 \mathrm{~mL})$. The resulting suspension was stirred at room temperature for overnight. The formations of white color precipitates were observed and solid was filtered, washed twice with diethyl ether. The white color solid was obtained. Yield: $4.24 \mathrm{~g}, 80 \%$. FT-IR $\left(\mathrm{KBr}, v / \mathrm{cm}^{-1}\right)$ : 3053.3 (Ar $\mathrm{C}-\mathrm{H}$ stretch), 1739.7 ( $\mathrm{C}=\mathrm{C}$ bending), 1435.0 (Ar C-C stretch), 1585.4 (C=N stretch), 686.6 (C-Br). ${ }^{1} \mathrm{H}$ NMR (400 MHz, DMSO- $\left.d_{6}, \delta \mathrm{ppm}\right)$ : 7.94-7.57 (m, 32H, Phenyl $\left.{ }^{1} \mathrm{H}\right), 4.75\left(\mathrm{~S}, 4 \mathrm{H},-\mathrm{CH}_{2}-\right.$ ). ${ }^{13} \mathrm{C}$ NMR (100 MHz, DMSO- $\left.d_{6}, \delta p p m\right): 152.64$, 135.39, 134.07, 133.97, 130.32, 130.20, 129.36, 125.1, 117.53, 116.6 (Ar C), $30.6\left(-\mathrm{CH}_{2}-\right)$.

\subsubsection{Synthesis of polymer PTVT}

$\mathrm{M}_{1}(0.5 \mathrm{~g}, 0.9 \mathrm{mmol})$ was dissolved in dry THF. To this solution $60 \% \mathrm{NaH}(4.53 \mathrm{mmol})$ was added as portion wise, then white color suspension was turned to purple color. After $\mathrm{M}_{2}(0.45 \mathrm{mmol})$ was added, the solution was stirred at $65^{\circ} \mathrm{C}$ for $24 \mathrm{~h}$. After cooling, the reaction mixture was diluted with water and the organic phase was extracted with ethyl acetate $(80 \mathrm{~mL} \times 2)$. After solvent evaporation, the crude product was recrystallized from isopropanol to give polymer PTVT as a yellow color solid. FT-IR ( $\mathrm{KBr}$, $\left.v / \mathrm{cm}^{-1}\right): 2922$ (aromatic $\mathrm{C}-\mathrm{H}$ stretch), $2853\left(-\mathrm{CH}_{3}\right.$ stretch), $1712.8(-\mathrm{C}=\mathrm{N}$ stretch $), 1618.5(\mathrm{C}=\mathrm{C}$ alkene stretch), 1455.1 (aromatic $\mathrm{C}=\mathrm{C}), 1215(\mathrm{C}-\mathrm{N}$ stretch), 933.5 (trans-vinylene). ${ }^{1} \mathrm{H}$ NMR $\left(\mathrm{CDCl}_{3}\right.$, $400 \mathrm{MHz}, \delta \mathrm{ppm}): 8.55$ (s, thiazole H), 7.21-7.18 ( $\mathrm{m}$, vinylene $\mathrm{H}$ nearer to thiazole), 7.08-6.95 (m, thiophene $\mathrm{H}), 6.94-6.87$ ( $\mathrm{m}$, vinylene $\mathrm{H}), 6.86-6.78$ (m, phenyl H), 4.1 (m, $\left.-\mathrm{OCH}_{2}-\right), 1.79-0.79$ (m, hexyl H).

\subsection{Synthesis of polymer PTVBT}

Polymer PTVBT was synthesized from $\mathrm{M}_{2}$ and $\mathrm{M}_{4}$ by using the above procedure.

FT-IR (KBr, $\left.v / \mathrm{cm}^{-1}\right)$ : 3022 (aromatic $\mathrm{C}-\mathrm{H}$ stretch), $2953.9\left(-\mathrm{CH}_{3}\right.$ stretch $), 1724.5(-\mathrm{C}=\mathrm{N}$ stretch $), 1623.9$ $(\mathrm{C}=\mathrm{C}$ alkene stretch), 1476 (aromatic $\mathrm{C}=\mathrm{C}), 1212.3$ (C-N stretch), 932.7 (trans-vinylene). ${ }^{1} \mathrm{H}$ NMR $\left(\mathrm{CDCl}_{3}, 400 \mathrm{MHz}, \delta \mathrm{ppm}\right)$ : 7.24-7.22 (m, benzoth- 
iadiazole $\mathrm{H}$ ), 7.20-7.18 ( $\mathrm{m}$, vinylene $\mathrm{H}$ nearer to $\quad 6.99-6.92(\mathrm{~m}$, vinylene $\mathrm{H}), 6.90-6.79$ ( $\mathrm{m}$, phenyl $\mathrm{H}$ ), benzothiadiazole), 7.08-7.00 ( $\mathrm{m}$, thiophene $\mathrm{H}), \quad 4.1\left(\mathrm{~m},-\mathrm{OCH}_{2}-\right), 1.79-0.79(\mathrm{~m}$, dodecyl $\mathrm{H})$.

Synthesis of donor moieties:

OH

1<smiles>CC(O)C(C)Br</smiles>

2

$\mathrm{OH}=\mathrm{C}_{6} \mathrm{H}_{13}(\mathrm{a})$

$\mathrm{OH}=\mathrm{C}_{12} \mathrm{H}_{25}$ (b)<smiles>CCCOc1cc(/C=C/c2ccc(C=O)s2)c(OCC)cc1/C=C/c1ccc(C=O)s1</smiles>

Monomer-2 $\left(\mathrm{M}_{2}\right)$<smiles>COc1cc(Br)c(OC)cc1Br</smiles>

$3 a \& 3 b$ $\underset{\substack{\text { Toluene } \\ 120^{\circ} \mathrm{C}, 40 \mathrm{hr}}}{\mathrm{SnBu}_{3}}$<smiles>C=Cc1cc(OCC)c(OCC)cc1OCCO</smiles>

$\begin{array}{rl}\mathrm{Pd}(\mathrm{OAC}), & \\ 140^{\circ} \mathrm{C}, 40 \mathrm{hr} & \mathrm{Br}\end{array}$<smiles>COc1cc(/C=C/c2ccc(C=O)s2)c(OC)cc1/C=C/c1ccc(C=O)s1</smiles>

Monomer-1 $\left(\mathrm{M}_{1}\right)$

Synthesis of acceptor moieties:

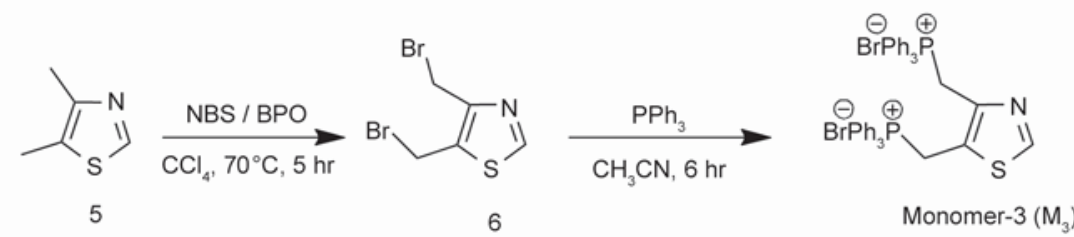

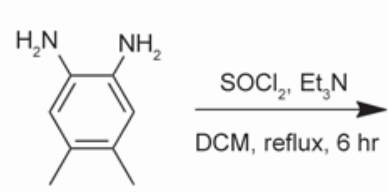

7

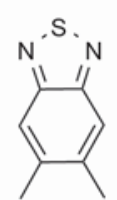

8

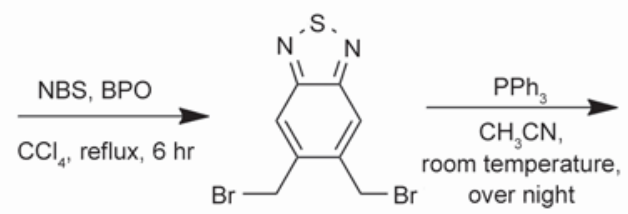

9

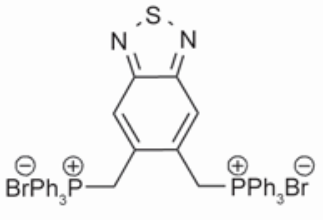

Monomer-4 $\left(\mathrm{m}_{4}\right)$

Synthesis of polymers:

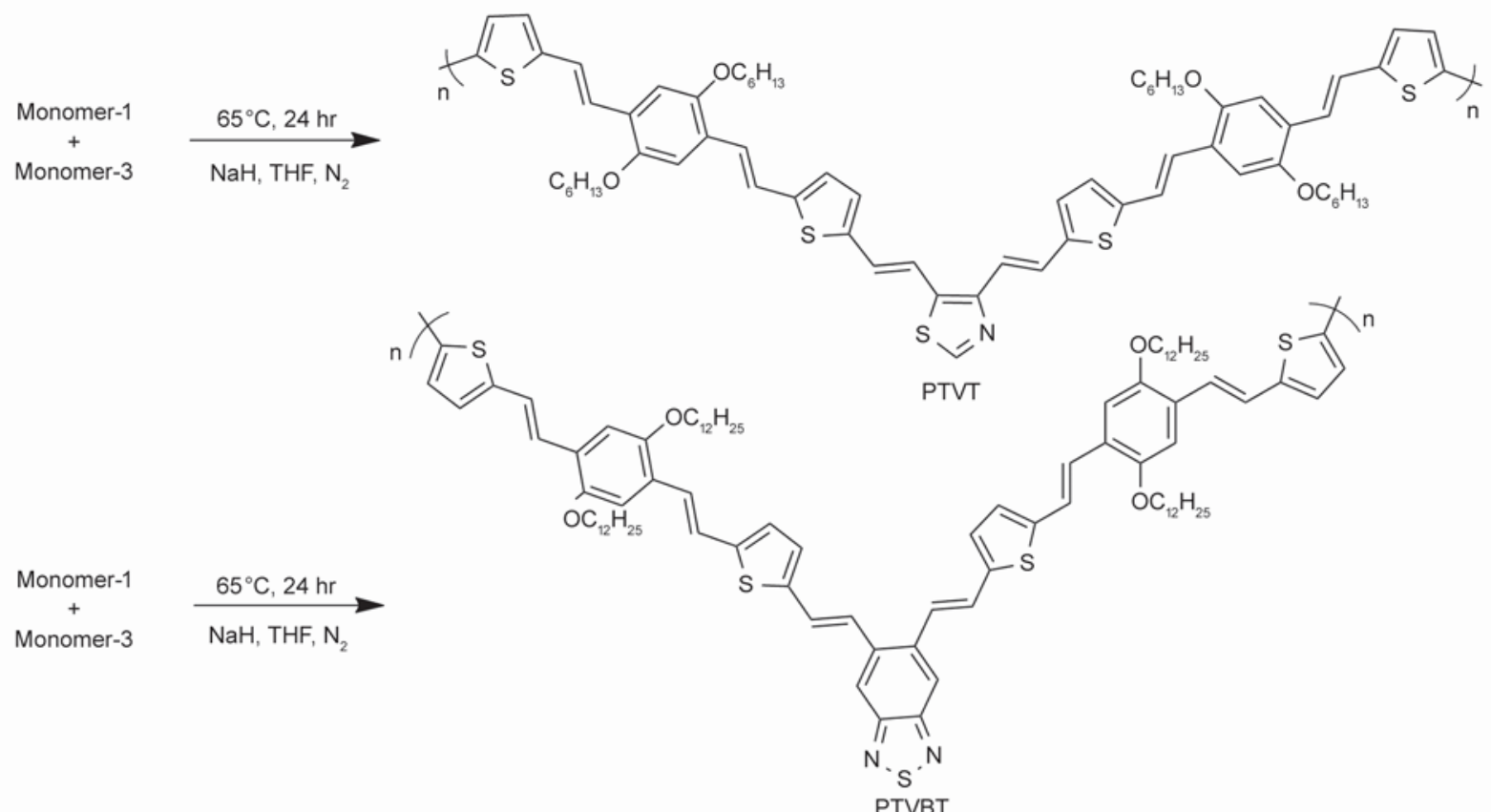

Figure 1. Synthesis route of the monomers and polymers 


\section{Results and discussion}

\subsection{Synthesis and structural characterization of monomers}

Figure 1 outlines the general synthetic procedure of monomers and polymers PTVT and PTVBT. The structures of intermediates, monomers, and polymers were confirmed by FT-IR and ${ }^{1} \mathrm{H}$ NMR. Intermediates $4 \mathrm{a}$ and $4 \mathrm{~b}$ were synthesized from hydroquinone by three-step reaction based on the previous literature $[22,23]$. The $\mathrm{M}_{1}$ and $\mathrm{M}_{2}$ were synthesized with a yield of $72 \%$ by Heck coupling of 5-bromothiophene-2-carbaldehyde and compound $4 \mathrm{a}, 4 \mathrm{~b}$ with $\mathrm{Pd}(\mathrm{OAc})_{2}$ as the catalyst. The aldehyde absorption band of the $\mathrm{M}_{1}$ and $\mathrm{M}_{2}$ appeared at $1641.2 \mathrm{~cm}^{-1}$ in FT-IR, 9.79 and $182.5 \mathrm{ppm}$ in ${ }^{1} \mathrm{H}$ and ${ }^{13} \mathrm{C} \mathrm{NMR}$ spectrum. The newly formed ethylene linkage signal was observed at $7.18 \mathrm{ppm}$ in ${ }^{1} \mathrm{H}$ NMR spectrum.

As shown in Figure 1, $\mathrm{M}_{3}$ was synthesized from dimethyl thiazole from previous literature [27]. The structure of the $\mathrm{M}_{3}$ was confirmed by sharp absorption band formed at 745.4 (C-P band), 685.2 (C-Br stretching) in FT-IR spectra and phenyl protons of phosphonium salt were observed at 7.96-7.66 ppm in NMR spectroscopy.

In the case of the $\mathrm{M}_{4}$ moiety, it was synthesized from 4,5-dimethyl-1,2-phenylenediamine as a starting material by three-step reactions. The structure of $\mathrm{M}_{4}$ was confirmed by sharp absorption bands at 1585.4 $(\mathrm{C}=\mathrm{N}$ stretch), $686.6(\mathrm{C}-\mathrm{Br})$ in FT-IR spectra and 30 phenyl protons of phosphonium salt was observed at 7.94-7.57 ppm in ${ }^{1} \mathrm{H}$ NMR analysis.

\subsection{Structural characterization of polymers}

The synthetic procedure of both polymers has been illustrated in Figure 1. Final polymers were synthesized using of Wittig condensation. The PTVT polymer was prepared from the $\mathrm{M}_{1}$ and $\mathrm{M}_{3}$ and PTVBT polymer was prepared from $\mathrm{M}_{2}$ and $\mathrm{M} 4$ using of $\mathrm{NaH}$ as a base under THF solvent. The dialdehydes $\left(\mathrm{M}_{1}\right.$ and $\mathrm{M}_{2}$ ) undergo $(2+2)$ cycloaddition with ylides $\left(\mathrm{M}_{3}\right.$ and $\left.\mathrm{M}_{4}\right)$ in the presence of $\mathrm{NaH}$ base and forms a zwitterionic intermediate called as betaine and it converts into four-membered cyclic oxaphosphetane intermediate. Later it was transformed to $(Z)$-alkene and phosphine oxide due to its stability. Here phosphine oxide stability acts as a driving force for the alkene (conjugated polymer) synthesis. The FT-IR (Figure 2) demonstrated that both polymers (PTVT and PTVBT) showed absorption bands at 933.5, $932.7 \mathrm{~cm}^{-1}$ which indicate the trans-vinylene is a

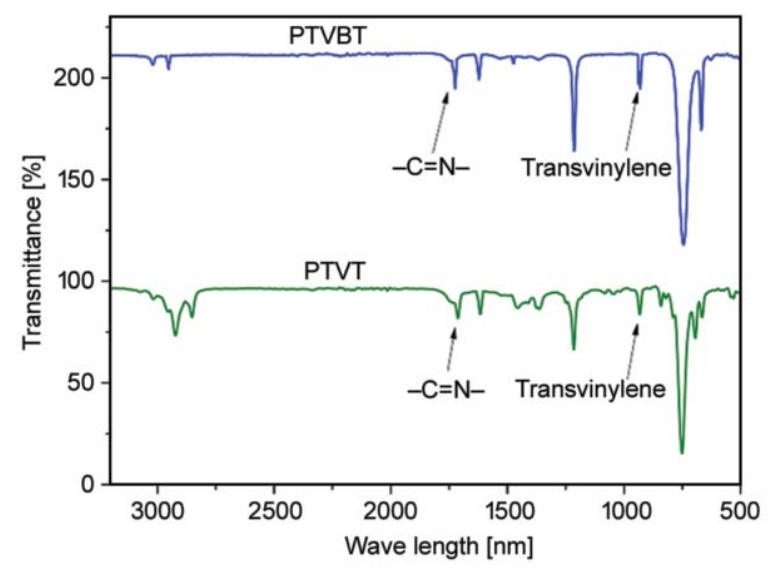

Figure 2. FT-IR spectra of both polymers

major product among newly formed vinylene bonds. The ${ }^{1} \mathrm{H}$ NMR spectra of both polymers are shown in Figure 3 and Figure 4. The polymer PTVT exposed downfield peak at $8.55 \mathrm{ppm}$, which represents thiazole proton. The trans-vinylene protons of both polymers peaks observed at 7.21-6.87 ppm which confirmed the successful polymerization of monomers. In PTVBT benzothiadiazole protons are observed at 7.24-7.22 ppm. In addition, remaining peaks showed good conformity with the resulting polymers. The synthesized polymers showed solubility in common organic solvents, such as toluene, chloroform, THF, diethyl ether at room temperature because of long alkoxy chains.

The number average molecular weight $\left(M_{\mathrm{n}}\right)$, the weight average molecular weight $\left(M_{\mathrm{w}}\right)$ and polydispersity index (PDI) were measured by gel permeation chromatography (GPC) against polystyrene standards using THF as eluent. GPC showed moderate molecular weights of PTVT has been found the $M_{\mathrm{n}}$ was $3942 \mathrm{Da}$ with PDI of 1.07 and for PTVBT has been found the $M_{\mathrm{n}}$ was $6201 \mathrm{Da}$ with PDI of 1.10. The lower polydispersity leads to the increase the efficiency of Polymer light-emitting diodes (PLEDs) [24]. Both polymers exhibited lower PDI than the recent literature of thienylene-biphenylene vinylene polymers [25].

\subsection{Optical characterization}

\subsubsection{Absorption studies}

Figure 5 shows the optical absorption properties of polymers in dilute THF solution $\left(5 \cdot 10^{-5} \mathrm{M}\right)$ and thin film state. In absorption spectra, both polymers exhibited two different types of absorption peaks. The first absorption peak appeared in the UV domain, which has shown the absorption maxima value at 


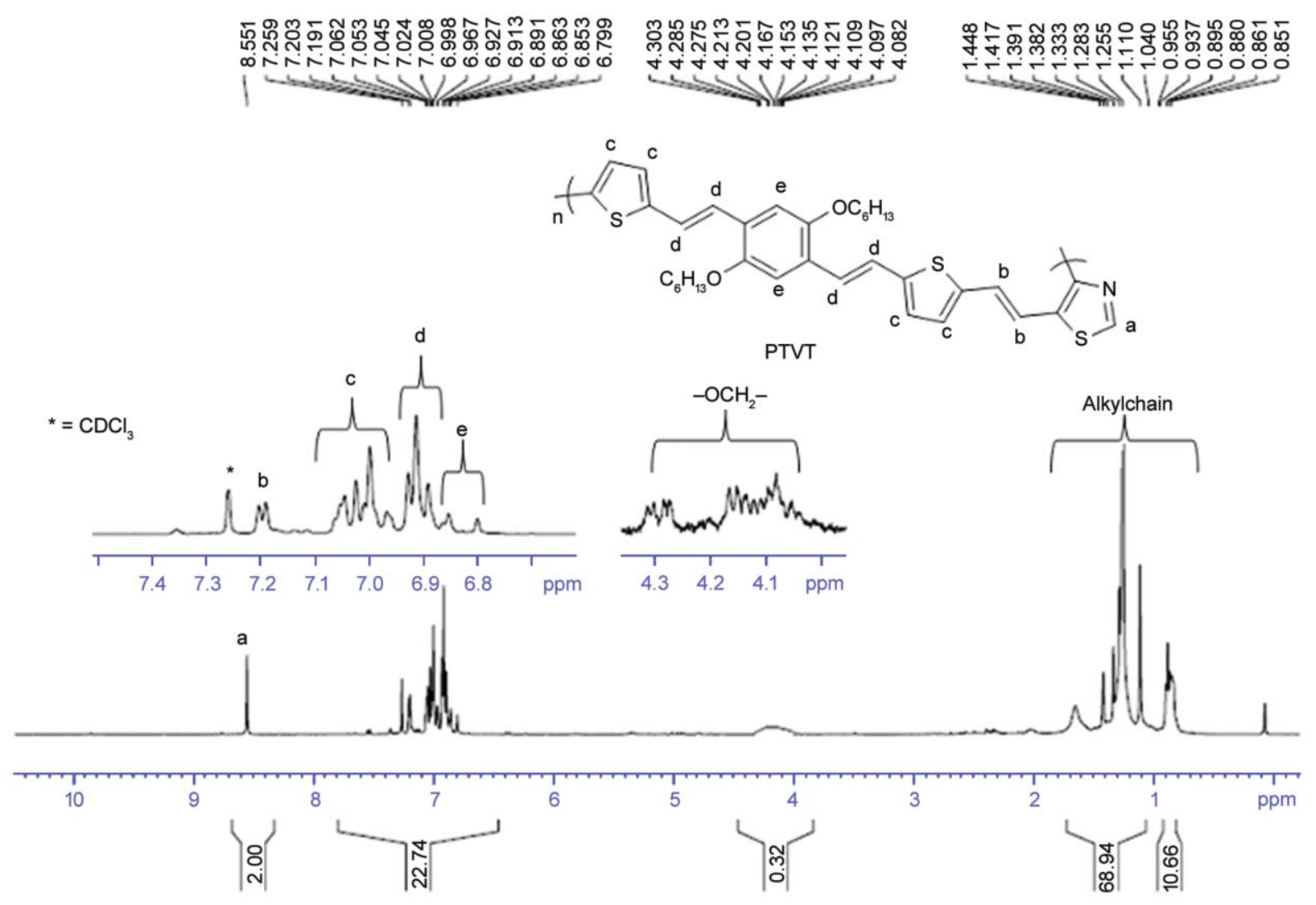

Figure 3. ${ }^{1} \mathrm{H}$ NMR spectra of the PTVT

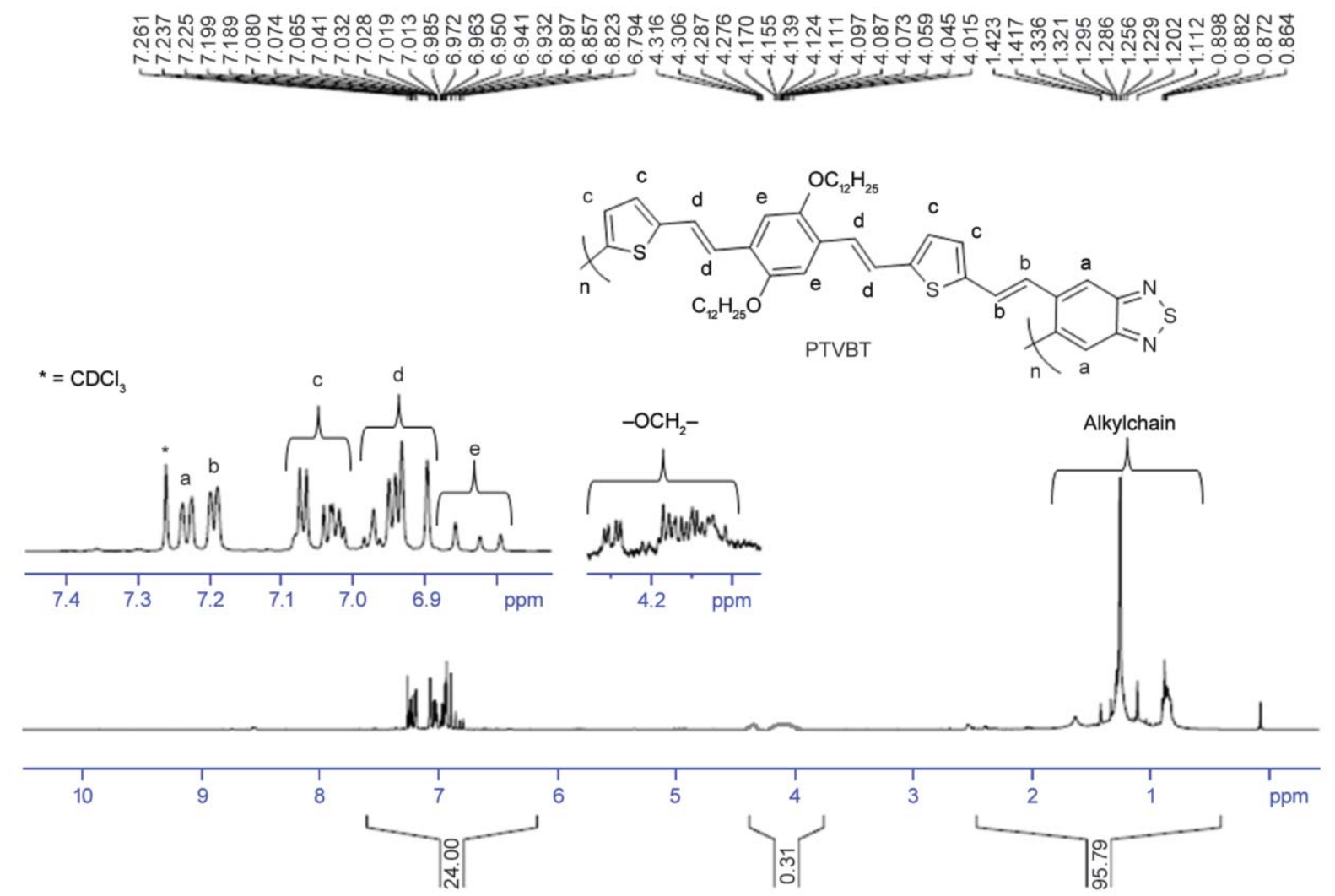

Figure 4. ${ }^{1} \mathrm{H}$ NMR spectra of the PTVBT 


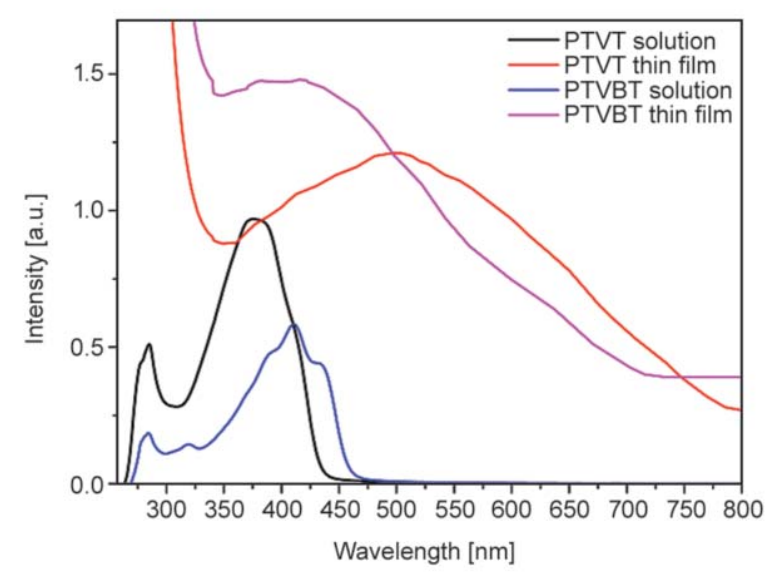

Figure 5. Absorption spectra of both polymers in THF solution and thin film state

$285 \mathrm{~nm}$ for both polymers due to $\pi-\pi^{*}$ electronic transition. In absorption spectra, absorption maxima value observed at 376 and $410 \mathrm{~nm}$ for respectively PTVT and PTVBT. This was attributed to the internal charge transfer $\left(n-\pi^{*}\right)$ between donor (thiophene bonded PPV) and acceptor (thiazole or benzothiadiazole). Shoulder peak was also observed at 393 and $437 \mathrm{~nm}$ for PTVBT and this was $36 \mathrm{~nm}$ red shifted whilst compared with PTVT because of strong charge transfer nature of benzothiadiazole.

In solid state film, absorption peaks are both broader and $41 \mathrm{~nm}$ red shifted with maxima which observed at 410 and $517 \mathrm{~nm}$ for respectively PTVT and PTVBT. The extensive red-shifted absorption peaks of both polymers in the thin film demonstrated the effect of $\pi$-stacking on the electronic structure of the polymer backbone, helped the planarity of the polymer chain and expanded the conjugation length in the thin film state. The optical band gap values determined from the absorption edge of the thin film spectra according to Equation (1) [17]:

$E_{\mathrm{g}}^{\mathrm{opt}}=\frac{1240}{\text { absorption onset equation }}$

For both polymers $E_{\mathrm{g}}^{\text {opt }}$ values calculated as 1.7 and $1.5 \mathrm{eV}$. It was a lower band gap than previously reported phenyl substituted poly( $p$-phenylene vinylene) polymer derivatives [26] and our previously reported thiophene and thiazole-based donor-acceptor conjugated polymer [27].

\subsubsection{Photoluminescence studies}

Figure 6 shows the fluorescence emission spectra of both polymers in dilute THF solution and thin film state. In solution state, PTVT showed strong bluish green fluorescent color with emission maxima at $457 \mathrm{~nm}$ without any shoulder. The other polymer PTVBT exhibited greenish yellow color fluorescent emission maxima at $487 \mathrm{~nm}$ with a shoulder at $464 \mathrm{~nm}$. The $30 \mathrm{~nm}$ red shift in emission spectra for polymer PTVBT, compared to PTVT, is accredited to the more expanded conjugation of alternative PPV-thiophene and benzothiadiazole segments and the stable donor-acceptor intermolecular interaction. It was red-shifted when compared with previously reported hexaphenylene end-capped tri( $p$-phenylene vinylene) derivatives [28].

Solid state emission of the polymers was observed through the thin films state. In a thin film, both the spectra of polymers were broader and red-shifted as compared to the THF solution. Thin film emission maxima were recorded at 496 and $510 \mathrm{~nm}$ for PTVT and PTVBT. This value was 39 and $23 \mathrm{~nm}$ red-shifted while compared with solution spectra. This red shift is correlated with interchain interactions of the polymeric backbone and $\pi-\pi$ stacking in the solid state. Moreover, the onset of polymers emission was almost similar in solution and thin film state, demonstrating that a conjugation hindrance exists, which is probably attributed to the non-coplanar system amongst phenylene vinylene and thiophene groups, that is the phenylene vinylene trans geometry along the chain averts coplanarity in the conjugated backbone owing to repulsion between the vinylene hydrogen and thiophene hydrogen and phenylene rings inducing to lower coplanarity.

Stokes shift was observed to find out the position of absorption and emission maxima. The lower Stokes shift was observed because of self-absorbing the emitted light. This may decrease the luminescence

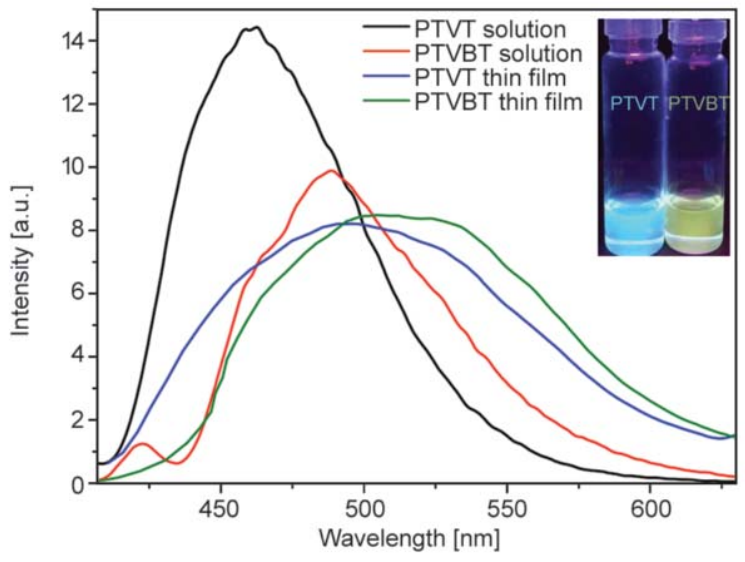

Figure 6. Fluorescence spectra of both polymers in THF solution and thin film state 
of the polymers. The Stokes shift was calculated according to the Equation (2):

$\Delta \lambda_{\text {Stokes }}=\lambda_{\text {max. emission }}-\lambda_{\text {max. absorption }}$

In our study, Stokes shift of PTVT and PTVBT were calculated as 81 and $77 \mathrm{~nm}$. This value is higher than previously published diketopyrrolopyrrole containing poly(phenylene) substituent [29]. In both polymers, PTVBT has strong benzothiadiazole acceptor because it contains more imine (good chromophore) groups than thiazole and also having more conjugation than thiazole. So it has been exhibited good luminescence characters.

\subsubsection{Fluorescence lifetime measurement}

Fluorescence lifetime was quantified to find the time of the present polymer spends time in the excited state before coming to the ground state. Figure 7 shows typical fluorescence lifetime (decay time) spectrum for the polymers PTVT and PTVBT with the emission wavelengths of 457 and $487 \mathrm{~nm}$. For both polymers, nanosecond time profiles were measured utilizing a time-correlated single photon counting method [30]. Investigation of the decay curve demonstrated that it could be fitted effectively with that two exponential decay function of the Equation (3):

$F(t)=A_{1} \mathrm{e}^{\frac{-t}{\tau_{1}}}$

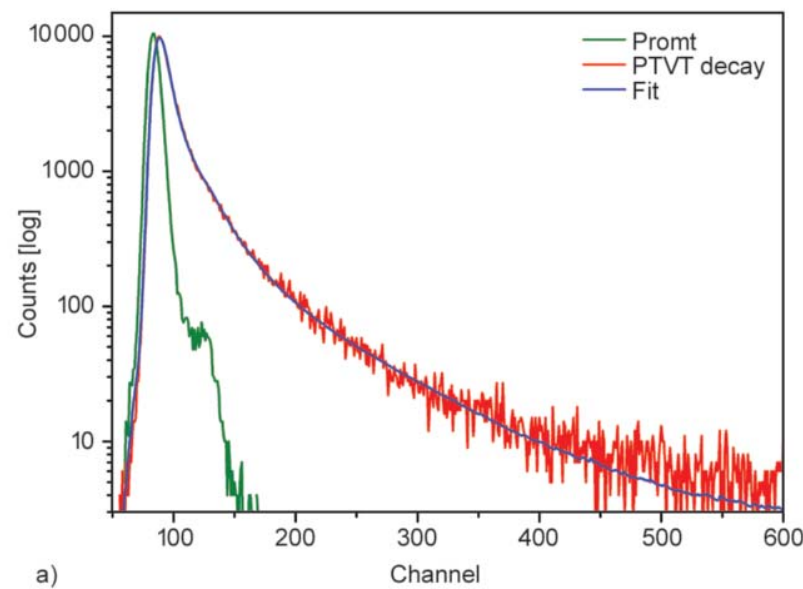

where $A$ is the amplitude of fluorescence intensity at time zero and $\tau$ is fluorescence decay time. The calculated parameters from the biexponential curves for PTVT and PTVBT were displayed in Table 1. The first lifetime $\left(\tau_{1}\right)$ of PTVT is $2.31 \mathrm{~ns}$ and a second lifetime $\left(\tau_{2}\right)=8.92 \mathrm{~ns}$ have the lowest $\chi^{2}$ fit (1.32). The reduced $\tau_{1}$ for PTVBT is $0.73 \mathrm{~ns}$ and $\tau_{2}=3.2 \mathrm{~ns}$ have the $1.08 \chi^{2}$ fit. The nature of the fit was assessed by the examination of the residuals, and the value of the decreased $\chi^{2}$ ratio [30].

\subsubsection{Measurement of quantum yield}

The importance and fundamental properties of photoluminescent materials were represented by quantum yield. The difference between the number of emitted photons and number of absorbed photons of the fluorophore is defined as quantum yield. Different approaches have been investigated to estimate this quantity, contingent on whether the fluorophore is in solid or in solution phase. The efficiency of organic devices was mainly dependent on the emission quantum yield, decay, and emission range. This is applicable for organic optoelectronic devices such as OLEDs [31].

In this study, the quantum yield can be measured by using quinine sulfate with $0.1 \mathrm{M} \mathrm{H}_{2} \mathrm{SO}_{4}$ solution as standard reference. The standard reference having absorption maxima and quantum yield was 350 and $0.54 \mathrm{~nm}$, which was used to calculate the relative

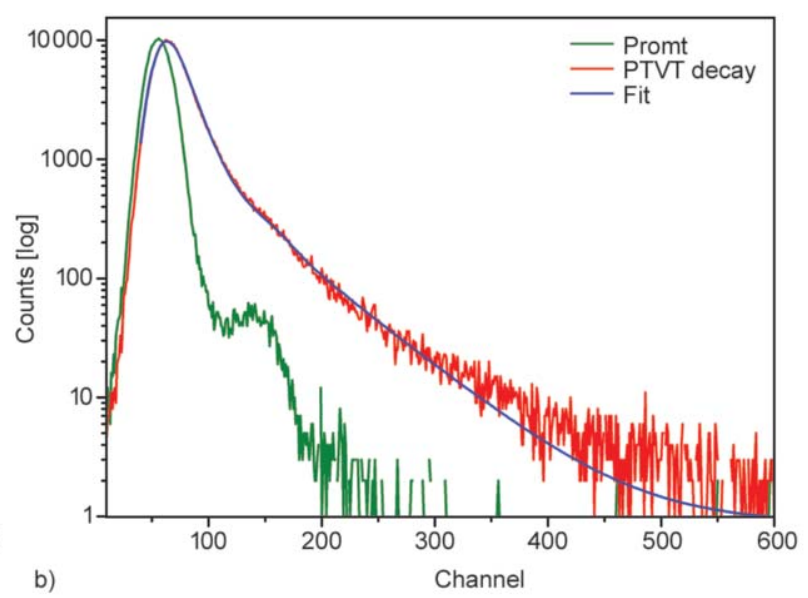

b)

Figure 7. Fluorescence Lifetime spectrum of (a) PTVT and (b) PTVBT

Table. 1 Fluorescence lifetime analysis data

\begin{tabular}{|c|c|c|c|c|c|c|}
\hline \multirow[t]{2}{*}{ Polymer } & \multirow[t]{2}{*}{ Analysis } & \multicolumn{2}{|c|}{$\begin{array}{c}\text { Lifetime } \\
{[\mathrm{ns}]}\end{array}$} & \multicolumn{2}{|c|}{ Amplitude } & \multirow[t]{2}{*}{$\chi^{2}$} \\
\hline & & $\tau_{1}$ & $\tau_{2}$ & $A_{1}$ & $A_{2}$ & \\
\hline PTVT & Two exponential & 2.31 & 8.92 & 33.63 & 12.34 & 1.32 \\
\hline PTVBT & Two exponential & 0.73 & 3.20 & 83.68 & 16.32 & 1.08 \\
\hline
\end{tabular}


quantum yield of our polymers. The relative quantum yields of polymers were calculated on the basis of Equation (4) [32]:

$\Phi=\Phi_{\mathrm{R}} \frac{I}{I_{\mathrm{R}}} \frac{O D_{\mathrm{R}}}{O D} \frac{n^{2}}{n_{\mathrm{R}}}$

where $\Phi$ quantum yield, $I$ integrated intensity of the emission spectra, $O D$ absorbance at the excitation wavelength, $n$ refractive index, $R$ reference fluorophore with a known quantum yield [33].

The quantum yield values of PTVT and PTVBT were found to be 0.35 and 0.39 , respectively in THF solution. The quantum efficiency of PTVBT is slightly higher than that of PTVT due to the lower energy of the emitting states, which may, in turn, promote nonradiative pathways [34]. According to electron transfer mechanism, the moderate quantum yield was noticed, owing to the photoinduced intramolecular charge transfer mechanism to take place between thiophene and thiazoles. This is a familiar aspect observed in donor-acceptor based conjugated polymers [35].

\subsubsection{Aggregation studies}

In aggregate stage, both polymeric luminophores exhibit reduced emission, this phenomenon is called ACQ. To exploit the possible ACQ characteristics of PTVT and PTVBT, we carried out their absorption (UV) and fluorescence (PL) nature under variation fractions of in THF/water. In both UV and PL studies, water fraction $\left(f_{\mathrm{w}}\right)$ was increased from 0 to $90 \%$. Figure 8a demonstrated that PTVT showed the $\pi-\pi^{*}$ electronic transition $\left(\lambda_{\max }\right)$ at $285 \mathrm{~nm}$ and $\mathrm{n}-\pi^{*}$ electronic transition at $376 \mathrm{~nm}$ in pure THF solvent. As water fraction increased from 0 to $60 \%$, the intensity of $\pi-\pi^{*}$ absorption peak was decreased gradually and red shifted up to $15 \mathrm{~nm}$ when $f_{\mathrm{w}}$ was allowed to increase from 60 to $90 \%$, the intensity of absorption peak was increased and blue shifted up to $2 \mathrm{~nm}$. On increasing the $f_{\mathrm{w}}$ from $0-60 \%$, the $\mathrm{n}-\pi^{*}$ peak also observed drastic changes and blue shifted up to $10 \mathrm{~nm}$ with lesser intensity. Then $f_{\mathrm{w}}$ increased from 60 to $90 \%$, the same peak has begun to show a blue shift $(2 \mathrm{~nm})$ with increasing intensity (Figure $8 \mathrm{a})$. Totally $12 \mathrm{~nm}$ blue shift of PTVT could exhibit $H$-aggregation with increasing $f_{\mathrm{w}}$ from 0 to $90 \%$ [36].

PTVBT and PTVT are also exhibiting similar properties which as shown in Figure $8 \mathrm{~b}$. The $\pi-\pi^{*}$ electronic transition of PTVBT $\left(\lambda_{\max }\right)$ was noted at $285 \mathrm{~nm}$ and $n-\pi^{*}$ electronic transition was assigned at $410 \mathrm{~nm}$ under THF solvent. While the $f_{\mathrm{w}}$ was increased from 0 to $60 \%, \pi-\pi^{*}$ absorption peak has shown gradual decreases of intensity with $35 \mathrm{~nm}$ redshift. Then $f_{\mathrm{w}}$ increased from 60 to $90 \%$, same absorption peak has shown $20 \mathrm{~nm}$ blue shift with higher intensity. But in the case of $n-\pi^{*}$ electronic transition peak, it has shown a lowering of intensity without any shift. Then $f_{\mathrm{w}}$ increased from 60 to $90 \%$, the intensity of absorption peak increased with $23 \mathrm{~nm}$ blue shift shown in the Figure $8 \mathrm{~b}$. The total $23 \mathrm{~nm}$ blue shift of PTVBT also could indicate $H$-aggregation with increasing of $f_{\mathrm{w}}$ from 60 to $90 \%$ [36]. The enormous amount of achievement is paid on tuning the $H$-aggregation stacking mode of both polymers by incorporating of hetero atoms with phenylene alkoxy side chains, creating the steric effect and outside strain [36, 37]. Excellent charge mobility could be achieved in this stacking pattern as proved by previous literature [38].

The PL spectra of dilute THF solution of PTVT $(10 \mu \mathrm{M})$ was transparent and displayed bluish green
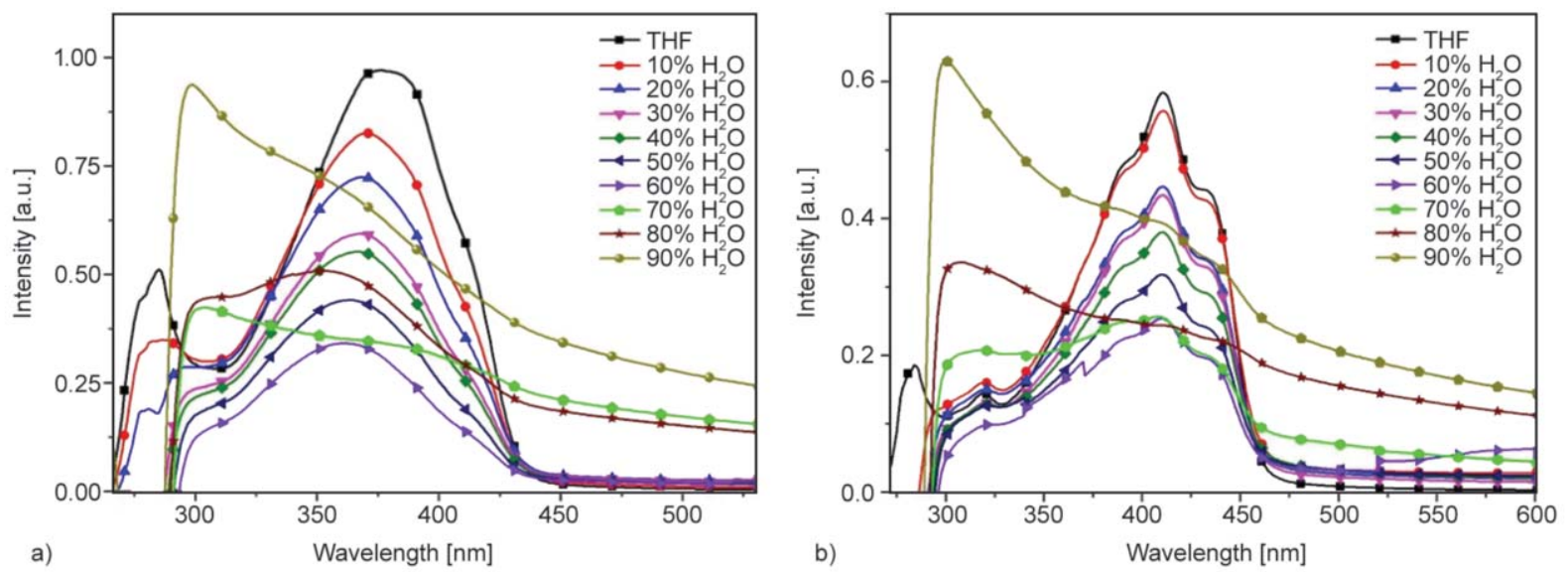

b)

Figure 8. UV-Vis spectra of (a) PTVT and (b) PTVBT in THF-water mixtures $(10 \mu \mathrm{M})$ with various water fractions $\left(f_{\mathrm{w}}\right)$ 

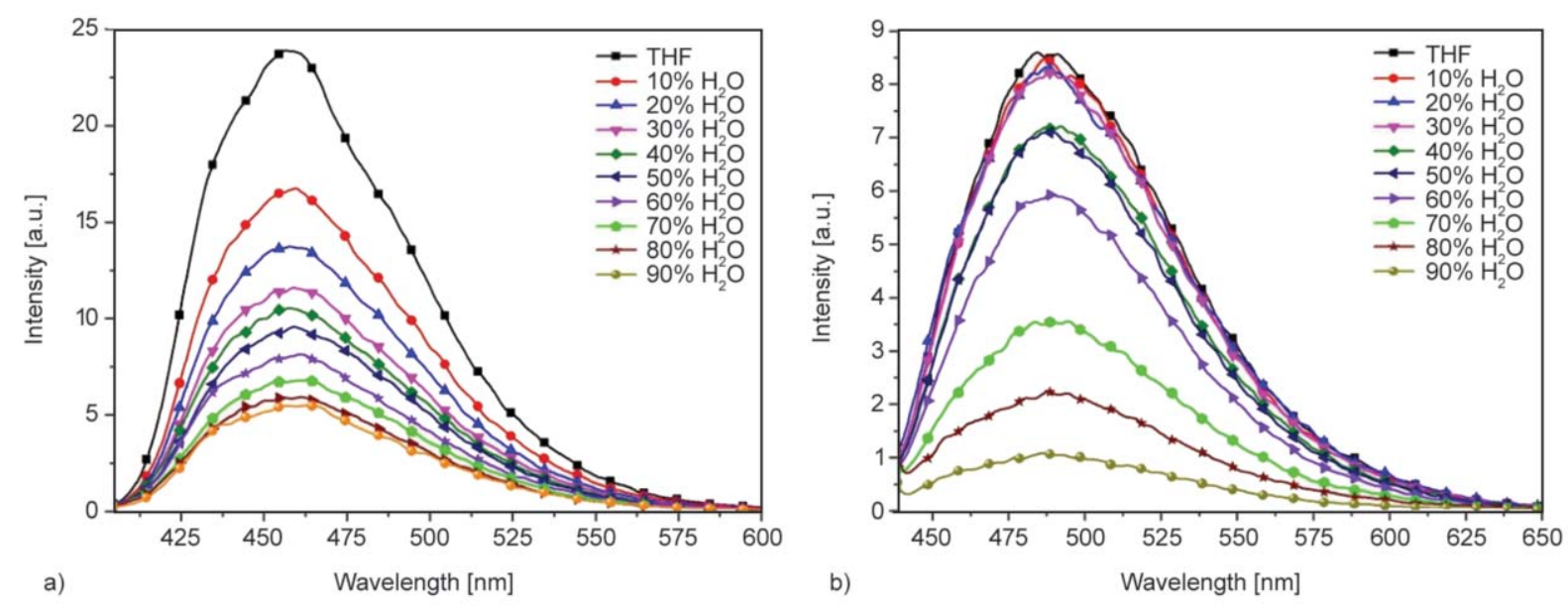

Figure 9. Changes in emission spectra (a) PTVT and (b) PTVBT in THF/water mixtures with different water fractions $\left(f_{\mathrm{w}}\right) 0-90 \%$

emission when excited at $457 \mathrm{~nm}$ at room temperature. When fw was increased to 0 to $90 \%$, which means PTVT starts the formation of aggregation from $f_{\mathrm{w}}=10$ to $90 \%$, the PL curves of PTVT began to show gradual decrease of fluorescence emission without altering the wavelength. This is clearly depicted in the Figure 9a. The reduced color emission picture was shown in the Figure 10a. The THF diluted PTVBT $(10 \mu \mathrm{M})$ solution display greenish yellow emission and excited at $487 \mathrm{~nm}$. In Figure 9b, it can be seen that the emission peak remains almost the same up to $50 \% f_{\mathrm{w}}$, which means the PTVBT resists the formation of aggregation. When $\mathrm{fw}$ was increased beyond $50 \%\left(f_{\mathrm{w}}=60-90 \%\right)$, the intensity of fluorescence decreased gradually. Weak fluorescence was observed at the water fractions of 80 and $90 \%$, which is shown in Figure 10b. This indicates

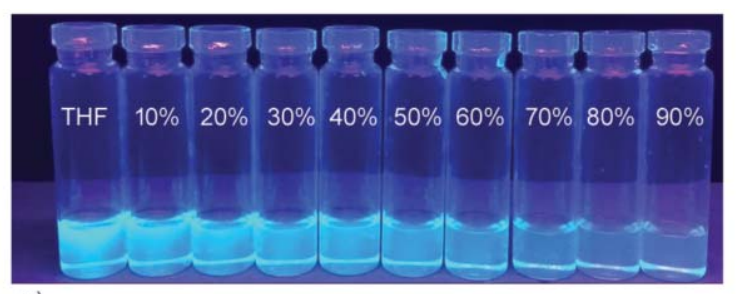

a)

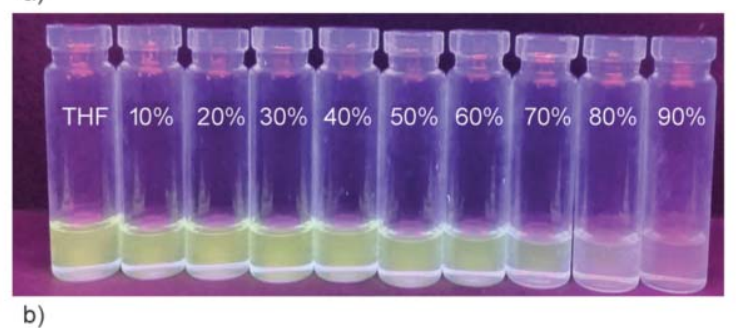

Figure 10. Visual changes to fluorescence emission photos of (a) PTVT and (b) PTVBT in THF/water mixtures with different water fractions $\left(f_{\mathrm{w}}\right) 0-90 \%$ under long UV lamp that both polymers (PTVT, PTVBT) confirmed the ACQ type of aggregation, which leads to decrease the fluorescence efficiency.

ACQ may be caused by the aggregation of luminophores. The aromatic rings of polymers having disc-like shapes, experience strong intermolecular $\pi-\pi$ stacking interactions. The excited states of corresponding aggregates often relax back or decay to the ground state by means of non-radiative channels, resulting in the emission weakened or quenching of the luminophores [39]. The aggregation of both polymer particles in THF-water mixture was further confirmed by SEM analysis which is shown in Figure 11. The usual radius of the PTVT aggregates decreased continuously from 4,2 to $1.5 \mu \mathrm{m}$ as the $f_{\mathrm{w}}$ was increased from 30,60, and $90 \%$ respectively. The PTVBT aggregates also decreased continuously from 5,3 to $1 \mu \mathrm{m}$ as the $f_{\mathrm{w}}$ was increased from 30,60 , and $90 \%$ respectively. The size of aggregates diminishes with raising $f_{\mathrm{w}}$ because of the rapid reduction in solvating (THF) power of solvent blends that is bolstered by SEM pictures. This perception has been reported in the literature [40]. ACQ effect is very demanding for OLEDs because of the guest molecules clump together, which diminish the brightness. When guest molecules are closer than ideal molecules, there is a chance for excited states to relax via nonradiative pathways. Each of these factors influences the efficiency and brightness of OLEDs and light-emitting electrochemical cell applications [20].

\subsection{Electrochemical properties}

The electrochemical properties of the polymers were carried out by cyclic voltammetry (CV). CV was performed to calculate the Highest occupied molecular 


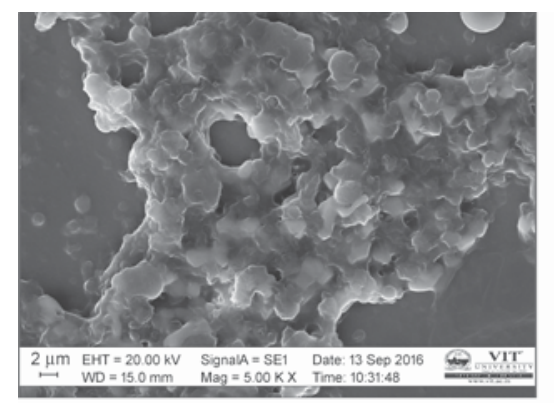

a)

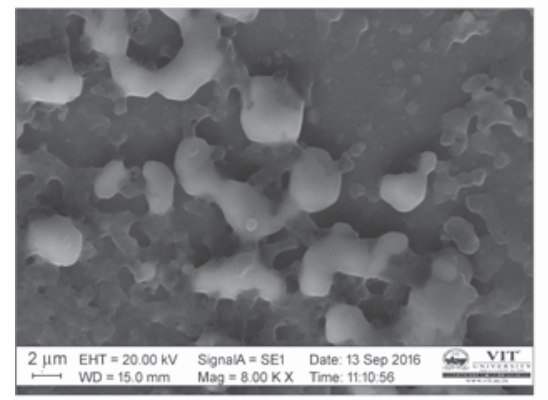

d)

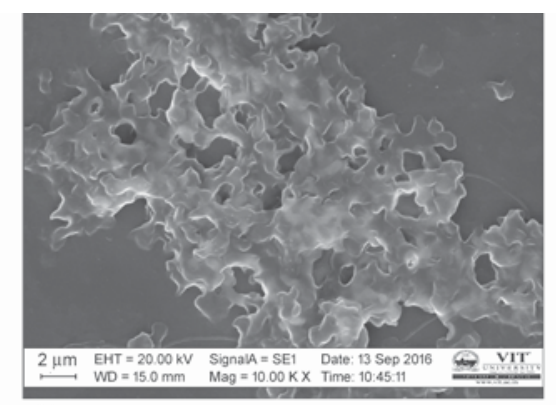

b)

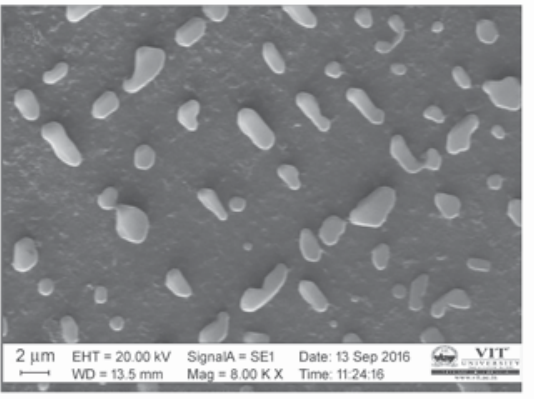

e)

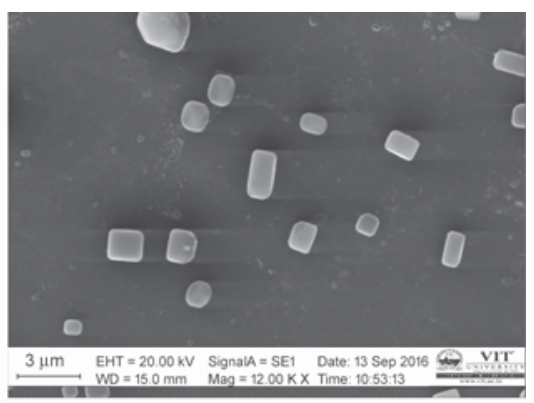

c)

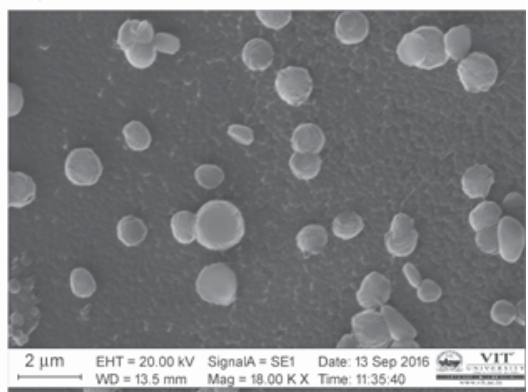

f)

Figure 11. SEM images of PTVT and PTVBT in THF/water mixtures: (a) PTVT in THF/ $\mathrm{H}_{2} \mathrm{O}(70 / 30$, v/v), (b) PTVT in $\mathrm{THF} / \mathrm{H}_{2} \mathrm{O}(40 / 60, \mathrm{v} / \mathrm{v})$, (c) PTVT in THF/ $\mathrm{H}_{2} \mathrm{O}(10 / 90, \mathrm{v} / \mathrm{v})$, (d) PTVBT in THF/ $\mathrm{H}_{2} \mathrm{O}(70 / 30, \mathrm{v} / \mathrm{v})$, (e) PTVBT in $\mathrm{THF} / \mathrm{H}_{2} \mathrm{O}(40 / 60, \mathrm{v} / \mathrm{v})$, (f) PTVBT in THF/ $\mathrm{H}_{2} \mathrm{O}(10 / 90, \mathrm{v} / \mathrm{v})$

orbital (HOMO) and Lowest unoccupied molecular orbital (LUMO) energy values from oxidation and reduction potential values of the polymer. Figure 12 shows the cyclic voltammograms of both polymers. Clearly, both polymers have positive (oxidation) and negative (reduction) peaks which indicate the wide distribution of donor and acceptor units in the system. The HOMO, LUMO and electrochemical band gap (Egec) value of both polymers were estimated using the reported empirical Equations (5-7) [41]:

$$
\begin{aligned}
& E_{\mathrm{HOMO}}=-\left(E_{\mathrm{ox}}+4,37\right) \\
& E_{\mathrm{LUMO}}=-\left(E_{\mathrm{red}}+4,37\right) \\
& E_{\mathrm{g}}=-\left(E_{\mathrm{HOMO}}-E_{\mathrm{LUMO}}\right)
\end{aligned}
$$

Table 2 shows the electrochemical energy level values of polymers. Both copolymers showed a transcendent anodic peak because of electron donating thienylene-PPV units and a strong reduction peak

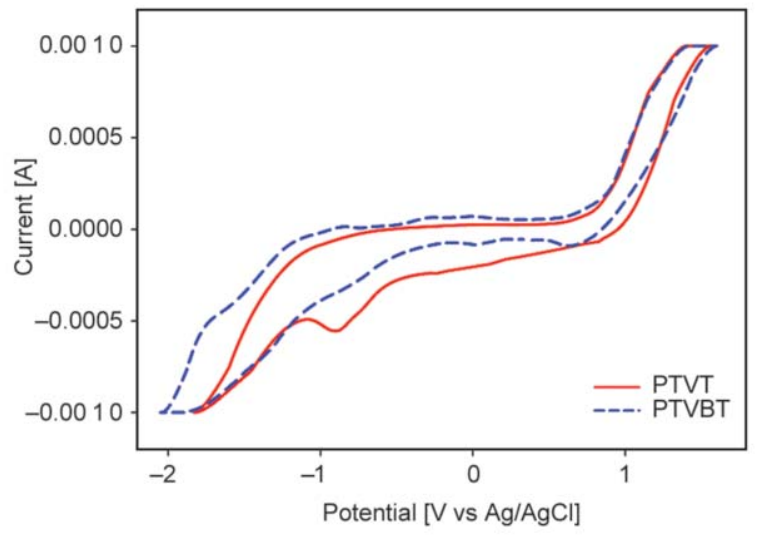

Figure 12. Cyclic voltammogram of PTVT \& PTVBT thin film on ITO glass in $0.1 \mathrm{M} \mathrm{Bu}_{4} \mathrm{NPF}_{6}$ of $\mathrm{CH}_{3} \mathrm{CN}$ solution with a scan rate $50 \mathrm{mV} / \mathrm{s}$

pertinent to the electron withdrawing thiazole and benzothiadiazole moieties. The onset oxidation $\left(E_{\mathrm{ox}}\right)$ and reduction $\left(E_{\mathrm{red}}\right)$ potentials of PTVT were 0.87 and $-0.53 \mathrm{~V}$ respectively. The HOMO and LUMO energy levels were -5.24 and $-3.84 \mathrm{eV}$ respectively

Table 2. Optical and electrochemical properties of PTVT and PTVBT

\begin{tabular}{|l|c|c|c|c|c|c|}
\hline \multicolumn{1}{|c|}{ Polymer } & $\begin{array}{c}\boldsymbol{E}_{\text {onset }}^{\mathbf{0 X}} \\
{[\mathbf{V}]}\end{array}$ & $\begin{array}{c}\boldsymbol{E}_{\mathbf{\text { onset }}}^{\text {red }} \\
{[\mathbf{V}]}\end{array}$ & $\begin{array}{c}\text { HOMO } \\
{[\mathbf{e V}]}\end{array}$ & $\begin{array}{c}\text { LUMO } \\
{[\mathbf{e V}]}\end{array}$ & $\begin{array}{c}\boldsymbol{E}_{\mathbf{g}}^{\text {ec }} \\
{\left[\mathbf{e V}^{\mathbf{a}}\right.}\end{array}$ & $\begin{array}{c}\boldsymbol{E}_{\mathbf{g}}^{\mathbf{O p t}} \\
{\left[\mathbf{e V}^{\mathbf{b}}\right.}\end{array}$ \\
\hline PTVT & 0.87 & -0.53 & -5.24 & -3.84 & 1.4 & 1.7 \\
\hline PTVBT & 0.80 & -0.50 & -5.17 & -3.87 & 1.3 & 1.5 \\
\hline
\end{tabular}

${ }^{\mathrm{a} E l e c t r i c a l}$ band gaps were calculated from using the equation, $E_{\mathrm{g}}=E_{\mathrm{HOMO}}-E_{\mathrm{LUMO}}$.

${ }^{\mathrm{b}}$ Optical band gaps were calculated from absorption edge of the thin film spectra according to $E_{\mathrm{g}}=1240$ /absorption onset 
and $E_{\mathrm{g}}^{\mathrm{ec}}$ was $1.4 \mathrm{eV}$. The onset $E_{\mathrm{ox}}$ and $E_{\text {red }}$ potentials of PTVBT were 0.80 and $-0.50 \mathrm{~V}$ respectively. The HOMO and LUMO energy levels are calculated were -5.17 and $-3.87 \mathrm{eV}$ respectively and $E_{\mathrm{g}}^{\mathrm{ec}}$ was $1.3 \mathrm{eV}$. Both polymers exhibited extremely lower band gap values, when compared with MDMO-PPV, MEH-PPV and P3HT polymers, which was represented in Figure 13. The electrochemical band gap values are lower in comparison with optical band gap values; this is a resemblance to previous reports, where the reported copolymers carrying alkoxy side groups [42]. The difference between absorption band gap and electrochemical band gap for PTVT is $0.3 \mathrm{eV}$, for PTVBT is $0.2 \mathrm{eV}$. Still, these different values were within the range of error $(0.2-0.5 \mathrm{eV})$ [43]. This can be attributed to the formation of free ions in an electrochemical experiment which distinguishes with optical absorption spectra. From these two polymers, PTVBT showed lower LUMO and band gap values because of two imine groups created a strong withdrawing nature towards benzothiadiazole. The band gap was lower when compared with anthracene and thiophene containing PPV [42]. Observation of lower band gap was due to fast charge transfer between thiophene donor and thiazole acceptor. These types of lower band gap polymers worked with great efficiency in the area of photovoltaic applications.

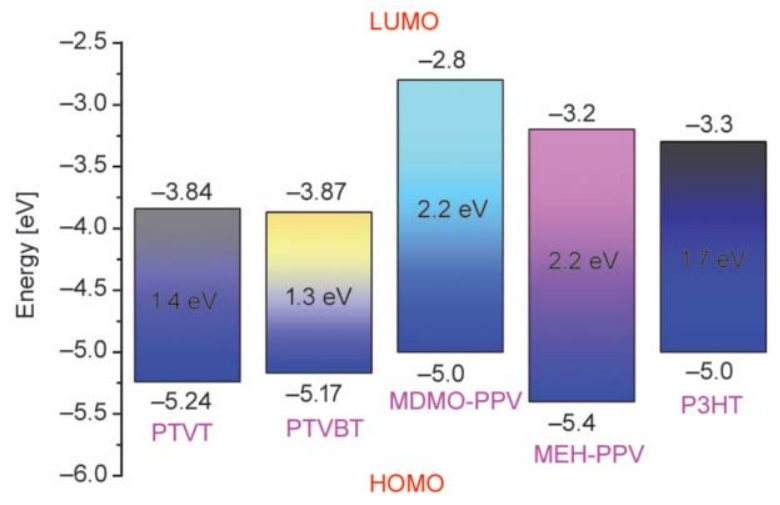

Figure 13. Schematic diagram of HOMO/LUMO and band gap energy levels of PTVT, PTVBT and comparison with MDMO-PPV, MEH-PPV, and P3HT polymers

\subsection{Surface morphology analysis}

AFM is a sort of microscopy with a fine-tapped test for examining the surface [44]. AFM is vital for the polymer characterization which gives data on surface topography. The morphology of both polymers was observed through polymer coated on glass plates. This coating was done by spin coating system. The morphology of the polymer's surface is very pertinent to polymer devices, charge transport and device lifetime. The surface morphology of both polymers was depicted in Figure 14. PTVT exhibited granule-shaped particles and that particle length was measured as $2.2 \mu \mathrm{m}$ and width was measured as $0.89 \mu \mathrm{m}$. PTVBT also exhibited granule-shaped particles and the particle size was measured as $3.8 \mu \mathrm{m}$.

AFM topography was also used to calculate the root mean square (RMS), the surface roughness $(S q)$, average surface roughness $(S a)$, peak-peak height $(S y)$, maximum peak height $(S p)$ and maximum peak-valley depth. All these surface measurements of polymers were represented in Table 3. The RMS surface roughness was noticed to be 36.2 and $48.2 \mathrm{~nm}$ for PTVTandPTVBT. These values were higher than PPV based dithenyl(thienothiadiazole)copolymer [45]. The higher surface roughness of the polymers is to increase the internal series resistance, internal light scattering, light absorption, and photocurrent of the device $[46,47]$. In AFM, both polymers exhibited good film-forming property due to good solubility with large domain size particles. The long alkyl chains (hexyloxy and dodecyloxy) affected the drying kinetics and self-organization of the polymers film during spin coating system which increased the particles domain size. Both polymers, PTVBT exhibited large domain size particles $(3.8 \mu \mathrm{m})$ due to the long alkyl chain (dodecyloxy chain) [48].

\subsection{Thermal analysis}

The thermal behavior of the polymer was measured by thermogravimetric analysis (TGA) and has shown in Figure 15. The temperature ramp rate is $10^{\circ} \mathrm{C} \cdot \mathrm{min}^{-1}$

Table 3. Surface morphology measurements of PTVT and PTVBT

\begin{tabular}{|c|c|c|c|c|c|c|}
\hline Polymer & $\begin{array}{c}\text { Average surface } \\
\text { roughness }(S a) \\
{[\mathrm{nm}]}\end{array}$ & $\begin{array}{c}\text { RMS roughness } \\
(S q) \\
{[\mathrm{nm}]}\end{array}$ & $\begin{array}{c}\text { Peak-peak } \\
\text { height }(S y) \\
{[\mathrm{nm}]}\end{array}$ & $\begin{array}{c}\text { Maximum peak } \\
\text { height }(S p) \\
{[\mathrm{nm}]}\end{array}$ & $\begin{array}{l}\text { Maximum peak- } \\
\text { valley depth }(S v) \\
{[\mathrm{nm}]}\end{array}$ & $\begin{array}{c}\text { Maximum peak- } \\
\text { valley }(S p-S v) \\
{[\mathrm{nm}]}\end{array}$ \\
\hline PTVT & 30.0 & 36.2 & 219.0 & 134.2 & -84.9 & 219.1 \\
\hline PTVBT & 34.8 & 48.2 & 346.4 & 86.1 & -260.3 & 346.4 \\
\hline
\end{tabular}



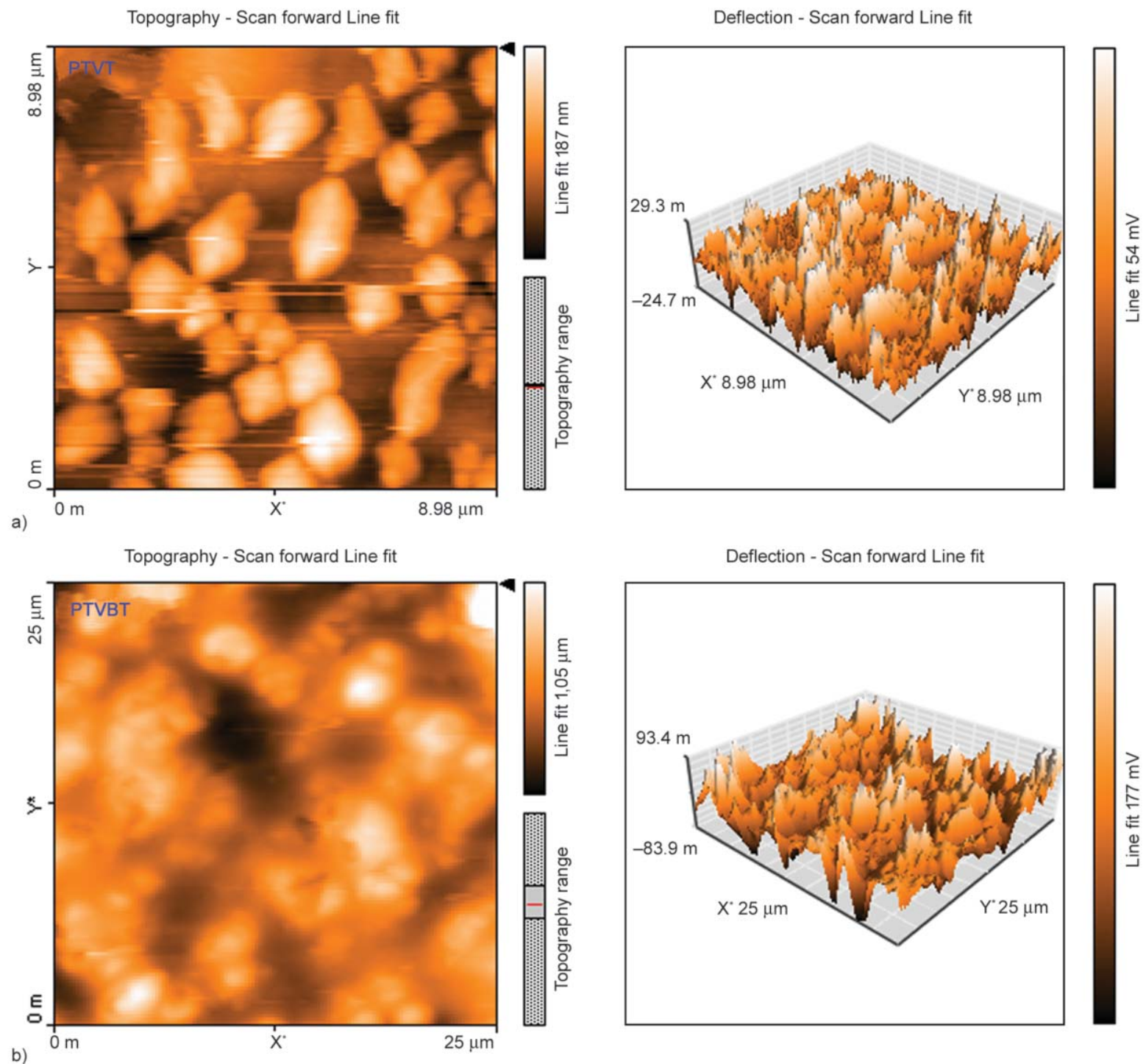

Figure 14. AFM morphology images of PTVT (a) and PTVBT

(b) polymers

under inert condition. Both polymers exhibited two stages of thermal decomposition. For PTVT the first decomposition temperature with $8 \%$ weight loss at $400^{\circ} \mathrm{C}$. The second stage of decomposition began at $640^{\circ} \mathrm{C}$ and continued up to $800^{\circ} \mathrm{C}$ with $52 \%$ weight loss. For PTVBT the first decomposition temperature with $6 \%$ weight loss at $460^{\circ} \mathrm{C}$. The second stage of decomposition began at $620^{\circ} \mathrm{C}$ and continued up to $800{ }^{\circ} \mathrm{C}$ with $60 \%$ weight loss The thermal stability of the polymers were enhanced by thienylene units functionalized alkoxy phenylene vinylene unit. From these two polymers, PTVBT has high thermal stability due to long alkoxy chain (dodecyl chain) and two imines bearing benzothiadiazole unit. The present polymer has higher thermal stability than previously reported anthracene- and thiophene containing MEH-PPEPPVs $\left(T_{\mathrm{d}}=379^{\circ} \mathrm{C}\right)[42]$. This kind of thermally sta- ble polymers will be tolerable for optoelectronic device applications.

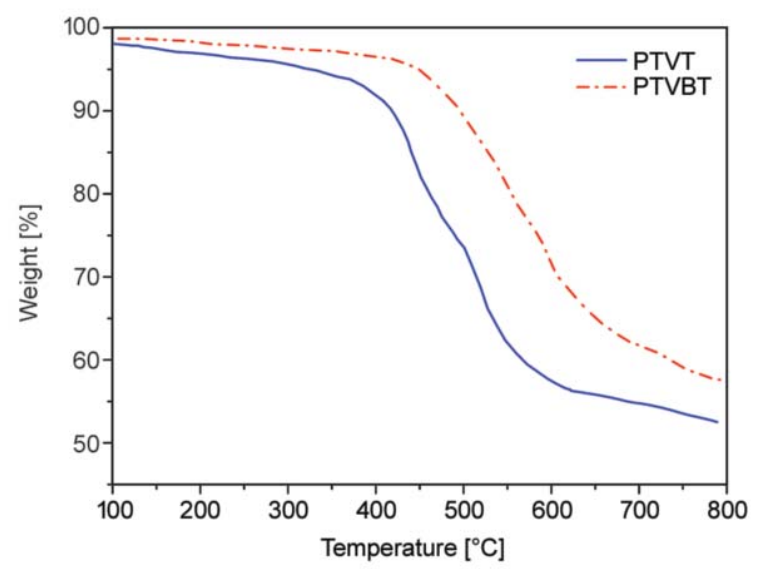

Figure 15. TGA thermogram of PTVT and PTVBT at a heating rate of $10^{\circ} \mathrm{C} \cdot \mathrm{min}^{-1}$ under nitrogen 


\subsection{Electrical conductivity}

The electrical conductivity of both polymers was carried out through impedance analysis. Impedance spectroscopy is an important and the most reliable technique with which to examine the electrical, dielectric properties of conjugated conductive polymeric materials. It gives a straight correlation among the response of an idealized system and a real model circuit composed of various electrical components [49]. The electronic conductivity of the polymers can be calculated by using Equation (8):

$\delta=\frac{1}{R_{\mathrm{b}}} \frac{d}{S}$

where $\delta$ is the electronic conductivity, $d$ thickness of polymer thin film, $R_{\mathrm{b}}$ bulk resistance, taken at the intersection among semi-circle and straight line, $S$ area of electrode.

Figure 16 shows the Nyquist plots for the PTVT and PTVBT. In the Nyquist plot, the real part of the impedance is plotted against the imaginary part at various frequencies. In Figure 16, it is obviously seen that there is an enlarged and clear semicircle in the lower frequency side and an inclined straight line in the higher frequency range. These diagrams resemble an ideal impedance spectrum. The conductivities of PTVT and PTVBT were found to be $5.98 \cdot 10^{-6}$ and $7.68 \cdot 10^{-6} \Omega^{-1} \cdot \mathrm{cm}^{-1}$. The calculated values of electrical conductivity are specified in Table. 4 . The

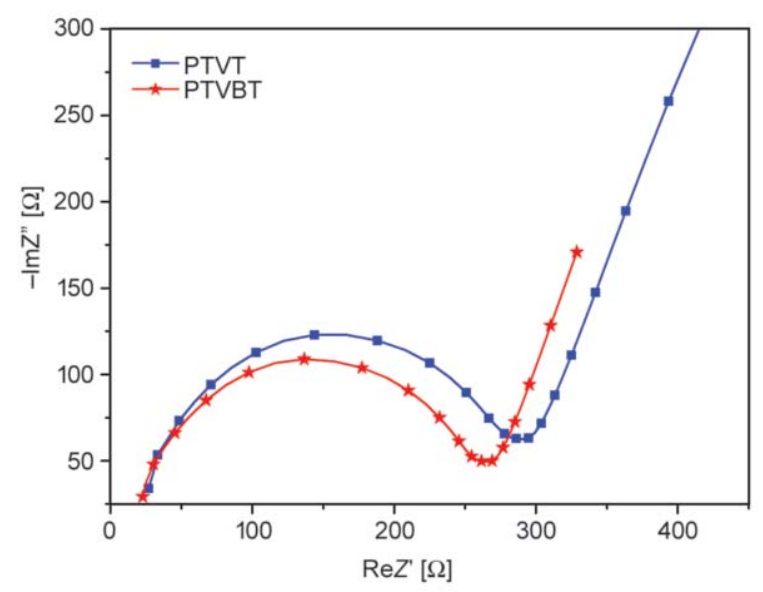

Figure 16. Electronic impedance spectra of the PTVT and PTVBT polymers conductivity value of the PTVBT polymer is higher than PTVT polymer. This may be due to the increase of electron mobility from thienylene-PPV to benzothiadiazole acceptor. These results demonstrate that the PTVBT polymer is advanced as compared to the other polymer both in electrical conductivity and optoelectronic properties.

\section{Conclusions}

We display here the synthesis of two new donor-acceptor type of thiophene containing phenylene vinylene and thiazole (PTVT), benzothiadiazole (PTVBT) based conjugated polymers through Wittig condensation. We have accomplished great solubility with the introduction of hexyloxy and dodecyloxy solubilizing groups. This solubility is favorable for film forming strategies. The polymers exhibited bright bluish green and greenish yellow fluorescence emission. PTVBT exhibited very short fluorescence decay times $(\tau)$ of $0.73 \mathrm{~ns}$ with high quantum yield. The ACQ studies showed that a fully reduced in fluorescence intensity of the polymer under in 90:10 water/THF mixture as contrasted to intact THF dissolved polymers and it was supported by SEM studies. We achieved the lower electrochemical band gaps 1.4 and $1.3 \mathrm{eV}$ for both polymers. These low band gap values are adaptable for solar cell preparations. The impedance measurements displayed that PTVBT exhibits the highest conductivity with a value of $7.68 \cdot 10^{-6} \Omega^{-1} \cdot \mathrm{cm}^{-1}$. PTVBT polymer was having good thermal stability up to $460{ }^{\circ} \mathrm{C}$. From these two polymers, PTVBT showed admirable optoelectronic properties because of two imines containing benzothiadiazole acceptor and longer alkoxy groups. These fascinating properties of polymers are helpful for the improvement of optoelectronic devices, such as OLEDs, solar cells, and organic thin film transistors etc.

\section{Acknowledgements}

This work was financially supported by DST-SERB, New Delhi (Grant no. SB/FT/CS-140/2013). The authors are grateful to DST/VIT-FIST, VIT University for providing instrumental facilities. The authors thank VIT University for providing 'VIT SEED GRANT' for carrying out this research work.

Table 4. Conductivities of both polymers determined by using electrochemical impedance spectroscopy

\begin{tabular}{|l|c|c|c|c|}
\hline \multicolumn{1}{|c|}{ Polymer } & $\begin{array}{c}\text { Thickness } \\
{[\mathbf{n m}]}\end{array}$ & $\begin{array}{c}\text { Resistance } \\
{[\boldsymbol{\Omega}]}\end{array}$ & $\begin{array}{c}\text { Area } \\
{\left[\mathbf{c m}^{\mathbf{2}}\right]}\end{array}$ & $\begin{array}{c}\text { Conductivity } \\
{\left[\mathbf{\Omega}^{-\mathbf{1}} \cdot \mathbf{c m}^{-\mathbf{1}}\right]}\end{array}$ \\
\hline PTVT & 1208.10 & 286 & 0.07 & $5.98 \cdot 10^{-6}$ \\
\hline PTVBT & 1408.67 & 262 & 0.07 & $7.68 \cdot 10^{-6}$ \\
\hline
\end{tabular}




\section{References}

[1] Cheng Y-J., Yang S-H., Hsu C-S.: Synthesis of conjugated polymers for organic solar cell applications. Chemical Review, 109, 5868-5923 (2009).

https://doi.org/10.1021/cr900182s

[2] Towns C. R., Grizzi I., Roberts M., Wehrum A.: Conjugated polymer-based light emitting diodes. Journal of Luminescence, 122-123, 976-979 (2007).

https://doi.org/10.1016/j.jlumin.2006.01.343

[3] Sirringhaus H., Tessler N., Friend R. H.: Integrated optoelectronic devices based on conjugated polymers. Science, 280, 1741-1744 (1998).

https://doi.org/10.1126/science.280.5370.1741

[4] Lin Z., Ma Y., Zheng X., Huang L., Yang E., Wu C-Y., Chow T. J., Ling Q.: Amide-based diarylmaleimide derivatives and polymers: Highly selective and ratiometric fluorescence sensing for anions. Dyes and Pigments, 113, 129-137 (2015). https://doi.org/10.1016/j.dyepig.2014.08.006

[5] Salbeck J.: Electroluminescence with organic compounds. Berichte der Bunsengesellschaft für physikalische Chemie, 100, 1666-1677 (1996).

https://doi.org/10.1002/bbpc.19961001002

[6] Lee S. H., Jang B-B., Tsutsui T.: Sterically hindered fluorenyl-substituted poly(p-phenylenevinylenes) for lightemitting diodes. Macromolecules, 35, 1356-1364 (2002). https://doi.org/10.1021/ma010643e

[7] Johansson D. M., Srdanov G., Yu G., Theander M., Inganäs O., Andersson M. R.: Synthesis and characterization of highly soluble phenyl-substituted poly(pphenylenevinylenes). Macromolecules, 33, 2525-2529 (2000). https://doi.org/10.1021/ma991582b

[8] Zrida H., Hriz K., Jaballah N., Sakly N., Kreher D., Madjoub M.: New poly(p-phenylenevinylene) derivatives containing isosorbide unit in the side-chain. Express Polymer Letters, 8, 709-722 (2014).

https://doi.org/10.3144/expresspolymlett.2014.74

[9] Jin Y., Ju J., Kim J., Lee S., Kim J. Y., Park S. H., Son S-M., Jin S-H., Lee K., Suh H.: Design, synthesis, and electroluminescent property of CN-poly(dihexylfluorenevinylene) for LEDs. Macromolecules, 36, 69706975 (2003).

https://doi.org/10.1021/ma025862u

[10] Gurge R. M., Sarker A. M., Lahti P. M., Hu B., Karasz F. E.: Light emitting properties of fluorine-substituted poly(1,4-phenylene vinylenes). Macromolecules, 30, 8286-8292 (1997). https://doi.org/10.1021/ma970693c

[11] Tang R., Tan Z., Cheng C., Li Y., Xi F.: Synthesis, electroluminescence, and photovoltaic properties of dendronized poly(p-phenylene vinylene) derivatives. Polymer, 46, 5341-5350 (2005).

https://doi.org/10.1016/j.polymer.2005.04.017
[12] Chen S. J., Zhang Q. Y., Gu J. W., Ma M. L., Zhang L., Zhou J., Zhou Y. Y.: A new conjugated polymer with donor-acceptor architectures based on alternating 1,4divinyl-2,5-dioctyloxybenzene and 5,8-(2,3-dipyridyl)quinoxaline: Synthesis, characterization, and photoinduced charge transfer. Express Polymer Letters, 6, 454464 (2012).

https://doi.org/10.3144/expresspolymlett.2012.48

[13] Zhen H., Xu W., Yang W., Chen Q., Xu Y., Jiang J., Peng J., Cao Y.: White-light emission from a single polymer with singlet and triplet chromophores on the backbone. Macromolecular Rapid Communication, 27, 2095-2100 (2006).

https://doi.org/10.1002/marc.200600565

[14] Zaifoglu B., Hacioglu O. S., Unlu N. A., Cirpan A., Toppare L.: Structure-property relations in donor-acceptor-donor type benzimidazole containing conjugated polymers. Journal of Materials science, 49, 225-231 (2014).

https://doi.org/10.1007/s10853-013-7696-8

[15] Sun X., Liu Y., Xu X., Yang C., Yu G., Chen S., Zhao Z., Qiu W., Li Y., Zhu D.: Novel electroactive and photoactive molecular materials based on conjugated donor-acceptor structures for optoelectronic device applications. The Journal of Physical Chemistry B, 109, 10786-10792 (2005). https://doi.org/10.1021/jp0509515

[16] Wu C-W., Lin H-C.: Synthesis and characterization of kinked and hyperbranched carbazole/fluorene-based copolymers. Macromolecules, 39, 7232-7240 (2006). https://doi.org/10.1021/ma061770j

[17] Liu D., Sun L., Du Z., Xiao M., Gu C., Wang T., Wen S., Sun M., Yang R.: Benzothiadiazole - An excellent acceptor for indacenodithiophene based polymer solar cells. RSC Advances, 4, 37934-37940 (2014).

https://doi.org/10.1039/C4RA06967F

[18] Palai A. K., Kumar A., Mishra S. P. M., Patri M.: Fluorene-based conjugated poly(arylene ethynylene)s containing heteroaromatic bicycles: Preparation and electro-optical properties. Journal of Materials Science, 49, 7408-7417 (2014).

https://doi.org/10.1007/s10853-014-8438-2

[19] Birks J. B.: Photophysics of aromatic molecules. Wiley, New York (1970).

[20] Xiang H., Cheng J., Ma X., Zhou X., Chruma J. J.: Near-infrared phosphorescence: Materials and applications. Chemical Society Reviews, 42, 6128-6185 (2013). https://doi.org/10.1039/C3CS60029G

[21] Feng X., Liu M., Pisula W., Takase M., Li J., Müllen K.: Supramolecular organization and photovoltaics of triangle-shaped discotic graphenes with swallow-tailed alkyl substituents. Advanced Materials, 20, 2684-2689 (2008).

https://doi.org/10.1002/adma.200800642 
[22] Baskar C., Lai Y-H., Valiyaveettil S.: Synthesis of a novel optically tunable amphiphilic poly(p-phenylene): Influence of hydrogen bonding and metal complexation on optical properties. Macromolecules, 34, 6255-6260 (2001). https://doi.org/10.1021/ma010366b

[23] Peng Q., Li M., Tang X., Lu S., Peng J., Cao Y.: New polyphenylene- and polyphenylenevinylene-based copolymers containing triarylpyrazoline units in the main chains. Journal of Polymer Science Part A: Polymer Chemistry, 45, 1632-1640 (2007). https://doi.org/10.1002/pola.21929

[24] Menon A., Dong H., Niazimbetova Z. I., Rothberg L. J., Galvin M. E.: Polydispersity effects on conjugated polymer light-emitting diodes. Chemistry of Materials, 14, 3668-3675 (2012). https://doi.org/10.1021/cm010936m

[25] Gopi V., Varma S. J., Mahesh Kumar M. V., Prathapan S., Jayalekshmi S., Joseph R.: Semiconducting thienylene-biphenylenevinylene hybrid polymers: Synthesis, characterization and application prospects in polymer LEDs. Dyes and Pigments, 126, 303-312 (2016). https://doi.org/10.1016/j.dyepig.2015.11.020

[26] Tang R., Xu X., Cheng C., Yu G., Liu Y., Xi F.: Synthesis and luminescence properties of novel phenylsubstituted poly(p-phenylene vinylene) derivatives. Synthetic Metals, 150, 63-71 (2005).

https://doi.org/10.1016/j.synthmet.2005.01.020

[27] Mahesh K., Karpagam S.: Synthesis and optoelectronic properties of thiophene donor and thiazole acceptor based blue fluorescent conjugated oligomers. Journal of Fluorescence, 26, 1457-1466 (2016). https://doi.org/10.1007/s10895-016-1838-8

[28] Jana D., Ghorai B. K.: Hexaphenylbenzene end-capped tri(p-phenylenevinylenes): Synthesis and properties. Tetrahedron Letters, 55, 5203-5206 (2014). https://doi.org/10.1016/j.tetlet.2014.07.099

[29] Zhang G., Xu H., Liu K., Li Y., Yang Y., Yang M.: Synthesis, characterization and comparative photovoltaic behavior of diketopyrrolopyrrole (DPP)-containing poly(phenylene vinylene)s varying at $N$-alkyl or 3,6aryl substituents in DPP units. Synthetic Metals, 160, 1945-1952 (2010). https://doi.org/10.1016/j.synthmet.2010.07.014

[30] Selvakumar S., Sivaji K., Arulchakkaravarthi A., Sankar S.: Enhanced fluorescence and time resolved fluorescence properties of p-terphenyl crystal grown by selective self seeded vertical Bridgman technique. Materials Letters, 61, 4718-4721 (2007).

https://doi.org/10.1016/j.matlet.2007.03.018

[31] Williams A. T. R., Winfield S. A., Miller J. N.: Relative fluorescence quantum yields using a computer-controlled luminescence spectrometer. Analyst, 108, 1067 1071 (1983).

https://doi.org/10.1039/AN9830801067
[32] Collado D., Casado J., González S. R., Navarrete J. T. L., Suau R., Perez-Inestrosa E., Pappenfus T. M., Raposo M. M. M.: Enhanced functionality for donor-acceptor oligothiophenes by means of inclusion of BODIPY: Synthesis, electrochemistry, photophysics, and model chemistry. Chemistry A European Journal, 17, 498-507 (2011). https://doi.org/10.1002/chem.201001942

[33] Qu J., Pschirer N. G., Liu D., Stefan A., de Schryver F. C., Müllen K.: Dendronized perylenetetracarboxdiimides with peripheral triphenylamines for intramolecular energy and electron transfer. Chemistry A European Journal, 10, 528-537 (2004).

https://doi.org/10.1002/chem.200304994

[34] Kim H. M., Seo M. S., Jeon S-J., Cho B. R.: Two-photon absorption properties of hexa-substituted benzene derivatives. Comparison between dipolar and octupolar molecules. Chemical Communications, 47, 7422-7424 (2009).

https://doi.org/10.1039/B916965B

[35] Hao X-T., McKimmie L. J., Smith T. A.: Spatial fluorescence inhomogeneities in light-emitting conjugated polymer films. The Journal of Physical Chemistry Letters, 2, 1520-1525 (2011). https://doi.org/10.1021/jz200540j

[36] Guo K., Gao Z., Cheng J., Shao Y., Lu X., Wang H.: Linear thiophene-containing $\pi$-conjugated aldehydes with aggregation-induced emission for building solid red luminophors. Dyes and Pigments, 115, 166-171 (2015). https://doi.org/10.1016/j.dyepig.2014.12.017

[37] Jeon S., Lee J. H., Lee I. K., Lee W. H., Kim B-G.: Side chain assisted different types of molecular aggregation and comparison of aggregation dependent field effect mobility. Dyes and Pigments, 133, 114-119 (2016). https://doi.org/10.1016/j.dyepig.2016.05.031

[38] Dong H., Fu X., Liu J., Wang Z., Hu W.: 25th anniversary article: Key points for high-mobility organic field-effect transistors. Advanced Materials, 25, 6158-6183 (2013). https://doi.org/10.1002/adma.201302514

[39] Mei J., Leung N. L., Kwok R. T., Lam J. W., Tang B. Z.: Aggregation-induced emission: Together we shine, united we soar. Chemical Reviews, 115, 11718-11940 (2015). https://doi.org/10.1021/acs.chemrev.5b00263

[40] Jia W-B., Wang H-W., Yang L-M., Lu H-B., Kong L., Tian Y-P., Yang J-X.: Synthesis of two novel indolo[3,2b]carbazole derivatives with aggregation-enhanced emission property. Journal of Materials Chemistry C, 1, 7092-7101 (2013). https://doi.org/10.1039/C3TC31590H

[41] Karpagam S., Guhanathan S.: Emitting oligomer containing quinoline group: Synthesis and photophysical properties of conjugated oligomer obtained by Wittig reaction. Journal of Luminescence, 145, 752-759 (2014). https://doi.org/10.1016/j.jlumin.2013.08.002 
[42] Wild A., Egbe D. A. M., Birckner E., Cimrová V., Baumann R., Grummt U-W., Schubert U. S.: Anthraceneand thiophene-containing MEH-PPE-PPVs: Synthesis and study of the effect of the aromatic ring position on the photophysical and electrochemical properties. Journal of Polymer Science Part A: Polymer Chemistry, 47, 2243-2261 (2009).

https://doi.org/10.1002/pola.23304

[43] Gao C., Qu B., Jiang Z., Tian D., Liu H., Chen Z., Xiao L., Gong Q.: Synthesis of a side chain conjugated polythiophene copolymer and its photovoltaic property. Synthetic Metals, 161, 864-868 (2011). https://doi.org/10.1016/j.synthmet.2011.02.014

[44] Yang Y-P., Tsay R-Y.: Morphology of compressed dipalmitoyl phosphatidylcholine monolayers investigated by atomic force microscopy. Journal of Luminescence, 127, 186-191 (2007). https://doi.org/10.1016/j.jlumin.2007.02.055

[45] Mikroyannidis J. A., Tsagkournos D. V., Balraju P., Sharma G. D.: Efficient bulk heterojunction solar cells using an alternating phenylenevinylene copolymer with dithenyl(thienothiadiazole) segments as donor and PCBM or modified PCBM as acceptor. Solar Energy Materials and Solar Cells, 95, 3025-3035 (2011).

https://doi.org/10.1016/j.solmat.2011.06.025
[46] Hoven C. V., Dang X-D., Coffin R. C., Peet J., Nguyen T-Q., Bazan G. C.: Improved performance of polymer bulk heterojunction solar cells through the reduction of phase separation via solvent additives. Advanced Materials, 22, E63-E66 (2010).

https://doi.org/10.1002/adma.200903677

[47] Krebs F. C., Gevorgyan S. A., Alstrup J.: A roll-to-roll process to flexible polymer solar cells: Model studies, manufacture and operational stability studies. Journal of Materials Chemistry, 19, 5442-5451 (2009). https://doi.org/10.1039/B823001C

[48] Duan C., Willems R. E. M., van Franker J. J., Bruijinaers B. J., Wienk M. M., Janssen R. A. J.: Effect of side chain length on the charge transport, morphology, and photovoltaic performance of conjugated polymers in bulk heterojunction solar cells. Journal of Materials Chemistry A, 4, 1855-1866 (2016). https://doi.org/10.1039/C5TA09483F

[49] Louati B., Hlel F., Guidara K.: Ac electrical properties and dielectric relaxation of the new mixed crystal $\left(\mathrm{Na}_{0.8} \mathrm{Ag}_{0.2}\right)_{2} \quad \mathrm{PbP}_{2} \mathrm{O}_{7}$. Journal of Alloys and Compounds, 486, 299-303 (2009).

https://doi.org/10.1016/j.jallcom.2009.06.148 